Seville, Spain, 26 September - 1 October 1994

The submitted manuscript has been authored by a contractor of the U. S. Government under contract $D E-A C 05-84 O R 21400$. Accordingly, the U. S. Government retains a nonexclusive, royalty free license to pubtish or reproduce the published torm of Gense to publish or reproduce the published lorm of his contibulion, or allow others to do so, for U. S Government purposes.

\title{
Energetic Particle Destabilization of Shear Alfvén Waves in Stellarators and Tokamaks
}

\author{
D. A. Spong, B. A. Carreras, C. L Hedrick, J-N. Leboeuf \\ Oak Ridge National Laboratory \\ P. O. Box 2009, Oak Ridge, TN 37831-8071
}

\author{
A. Weller \\ Max-Planck-Institut für Plasmaphysik, IPP-EURATOM-Association \\ D-85748 Garching, Germany
}

IAEA-CN-60/D-P-II-3

\section{DISCLAIMER}

\begin{abstract}
This report was prepared as an account of work sponsored by an agency of the United States Government. Neither the United States Government nor any agency thereof, nor any of their employees, makes any warranty, express or implied, or assumes any legal liability or responsibility for the accuracy, completeness, or usefulness of any information, apparatus, product, or process disclosed, or represents that its use would not infringe privately owned rights. Reference herein to any specific commercial product, process, or service by trade name, trademark, manufacturer, or otherwise does not necessarily constitute or imply its endorsement, recommendation, or favoring by the United States Government or any agency thereof. The views and opinions of authors expressed herein do not necessarily state or reflect those of the United States Government or any agency thereof.
\end{abstract}

\section{4. DLSTRIBUTION OF THIS DOCUMENT IS UNLMMTED $T R$}

\footnotetext{
*Research sponsored by the Office of Fusion Energy, U.S. Department of Energy, under contract DE-ACOS$840 R 21400$ with Martin Marietta Energy Systems. Inc.

This is a preprint of a paper intended for presentation at a scientific meeting. Because of the provisional nature of its content and since changes of substance or detail may have to be made before pudication, the preprint is made available on the understanding that it will not be cited in the literature or in any way be reproduced in its present form. The views expressed and the statements made remain the responsibility of the named author(s): the views do not necessarily reflect those of the government of the designating Member Stateisi or of the designatıng organization(s). In particular, neither the IAEA nor anV other organization or bodv sponsoring this meeting can be heid responsible for any material ieproduced in this preprint.
} 


\section{DISCLAIMER}

Portions of this document may be illegible in electronic image products. Images are produced from the best available original document. 


\title{
IAEA-CN-60/D-P-II-3
}

\section{Energetic Particle Destabilization of shear Alfvén Waves in Stellarators and Tokamaks}

\begin{abstract}
An important issue for ignited devices is the resonant destabilization of shear Alfvén waves by energetic populations. These instabilities have been observed in a variety of toroidal plasma experiments in recent years., including: beamdestabilized toroidal Alfvén instabilities (TAE) in low magnetic field tokamaks, ICRF destabilized TAE's in higher field tokamaks, and global Alfvén instabilities (GAE) in low shear stellarators. In addition, excitation and study of these modes is a significant goal of the TFTR-DT program and a component of the ITER physics tasks. We have developed a gyrofluid model which includes the wave-particle resonances necessary to excite such instabilities. The TAE linear mode structure is calculated nonperturbatively, including many of the relevant damping mechanisms, such as: continuum damping, non-ideal effects (ion FLR and electron collisionality), and ion/electron Landau damping. This model has been applied to both linear and nonlinear regimes for a range of experimental cases using measured profiles.
\end{abstract}

\section{Gyrofluid Model}

In order to analyze both the linear [1] and nonlinear [2] phases of shear Alfvén instabilities within a unified approach, we have developed a gyrofluid model with Landau closure based on a two-pole approximation to the plasma dispersion relation. By construction, this includes the inverse Landau growth effects necessary to drive the otherwise stable toroidal and global Alfvén eigenmodes unstable. The linear model used for the background plasma and fields consists of an Ohm's law and vorticity equation, as given below.

$$
\begin{aligned}
& \frac{\partial \tilde{\psi}}{\partial t}=\vec{\nabla}_{\|} \tilde{\phi}+\frac{T_{e}}{m_{i} \omega_{c i}^{2}}\left(i \frac{k_{\| 1}^{2}}{\omega} R_{e i}\right)_{\text {imag. }} \nabla_{\perp}^{2} \tilde{\psi} \\
& \frac{\partial \mathrm{U}}{\partial t}=-\vec{\nabla}_{11}\left(\frac{\tilde{\mathrm{J}}_{\phi}+\mathrm{J}_{\text {Q.eq }}}{\mathrm{B}_{\varphi}}\right)+\left[\hat{\mathrm{e}}_{\varphi} \times \vec{\nabla}\left(\frac{\mathrm{R}}{\mathrm{B}_{\varphi}}\right)\right] \cdot \vec{\nabla} \tilde{\mathrm{p}}_{\alpha}+\omega_{\text {real }} \rho_{\mathrm{i}}^{2} \nabla_{\perp}^{2} U-\frac{\mathrm{c}^{2} \beta_{\text {avg }}\left(\mathrm{S}_{\mathrm{ei}}\right)_{\text {imag. }}}{8 \pi \omega_{\text {real }}} \boldsymbol{\Omega}_{\mathrm{g}}^{2}(\phi)
\end{aligned}
$$

Here $R_{e i}^{-1}=1+Y_{0 e} / D_{e}+\tau_{i}^{-1}\left(1+Y_{0 i} / D_{i}\right), \quad \tau_{i}=T_{i} / T_{e}, D_{j}=1+\left(i v_{j} / \omega\right) Y_{0 j}$,

$$
\begin{aligned}
& \mathrm{Y}_{0 \mathrm{j}}=\xi_{\mathrm{j}} \mathrm{Z}\left(\zeta_{\mathrm{j}}\right), \xi_{\mathrm{j}}=\omega / \sqrt{2} \mathrm{k}_{\| \mathrm{l}} \mathrm{v}_{\mathrm{th} . \mathrm{j}}, \zeta_{\mathrm{j}}=\left(\omega+\mathrm{i} \nu_{\mathrm{j}}\right) \xi_{\mathrm{j}} / \omega, \Omega_{\mathrm{j}} \equiv(\hat{\mathrm{b}} \times \vec{\nabla} \mathrm{B}) \bullet \vec{\nabla} \\
& \mathrm{Y}_{\mathrm{ij}}=\xi_{\mathrm{j}}\left[\zeta_{\mathrm{j}}+\left(0.5+\zeta_{\mathrm{j}}^{2}\right) \mathrm{Z}\left(\zeta_{\mathrm{j}}\right)\right], \mathrm{Y}_{2 \mathrm{j}}=\xi_{\mathrm{j}}\left[1.5 \zeta_{\mathrm{j}}+\zeta_{\mathrm{j}}^{3}+\left(0.5+\zeta_{\mathrm{j}}^{2}+\zeta_{\mathrm{j}}^{4}\right) \mathrm{Z}\left(\zeta_{\mathrm{j}}\right)\right] \text {, and } \\
& \mathrm{S}_{\mathrm{ei}}=\mathrm{Y}_{2 \mathrm{e}}+\tau_{\mathrm{i}} \mathrm{Y}_{2 \mathrm{i}}-\mathrm{i} \frac{\nu_{\mathrm{e}}}{\omega} \frac{\mathrm{Y}_{1 \mathrm{e}}^{2}}{\mathrm{D}_{\mathrm{e}}}-\mathrm{i} \frac{\nu_{\mathrm{i}}}{\omega} \frac{\mathrm{Y}_{1 \mathrm{i}}^{2}}{\mathrm{D}_{\mathrm{i}}}+\mathrm{R}_{\mathrm{ie}}\left(\frac{\mathrm{Y}_{\mathrm{le}}}{\mathrm{D}_{\mathrm{e}}}-\frac{\mathrm{Y}_{1 \mathrm{i}}}{\mathrm{D}_{\mathrm{i}}}\right)^{2} ;
\end{aligned}
$$

Here $2 \pi \tilde{\psi}, U$, and $-\tilde{\phi} / B_{0}$ are the fluctuating poloidal magnetic flux, toroidal component of vorticity and electrostatic potential, respectively. The vorticity equation (2) includes a finite ion FLR term and Landau damping on the background 
ions and electrons. In order to model the global Alfvén instability, which is observed in rather collisional conditions on W7AS, ion and electron collisions are included in the Landau damping terms. These tend to broaden and reduce the maxima in the ion and electron resonances. The Ohm's law includes a generalized resistivity which takes into account both the usual collisional resistive effects as well as collisionless effects, consistent with the presence of a finite E\|. These nonideal collisionless effects arise due to the high frequency, non-resonant $(k \| \neq 0)$ nature of the Alfvén modes and the resulting incomplete cancellation of $E_{\|}$by the thermal electrons. The fast ion species (denoted by subscript $\alpha$ ) is described by the following two equations for its perturbed density $\left(\tilde{\mathrm{n}}_{\alpha}\right)$ and parallel velocity moments $\left(\tilde{\mathrm{V}}_{\mathrm{\|} \alpha}\right)$ :

$$
\begin{aligned}
& \frac{\partial \tilde{\mathrm{n}}_{\alpha}}{\partial \mathrm{t}}=\frac{\mathrm{n}_{0 \alpha} \mathrm{T}_{0 \alpha}}{\mathrm{M}_{\alpha} \Omega_{c \alpha}}\left\{\mathrm{n}_{0 \alpha}^{-1} \Omega_{\mathrm{u}}\left(\tilde{\mathrm{n}}_{\alpha}\right)+\mathrm{q}_{\alpha} \mathrm{T}_{0 \alpha}^{-1}\left[\Omega_{\mathrm{g}}(\tilde{\phi})-\mathrm{L}_{\mathrm{n} \alpha}^{-1} \frac{1}{\mathrm{r}} \frac{\partial \tilde{\phi}}{\partial \theta}\right]\right\}-\mathrm{n}_{0 \alpha} \nabla_{\|}^{(0)} \tilde{\mathrm{V}}_{\| \alpha \alpha}, \\
& \frac{\partial \tilde{\mathrm{V}}_{\| \alpha}}{\partial t}=\frac{\mathrm{T}_{0 \alpha}}{\mathrm{M}_{\alpha} \Omega_{c \alpha}}\left[\Omega_{\mathrm{g}}\left(\tilde{\mathrm{V}}_{\| \alpha}\right)-\frac{\mathrm{q}_{\alpha}}{\mathrm{M}_{\alpha} \mathrm{RL}} \frac{1}{\mathrm{n} \alpha} \frac{\partial \tilde{\psi}}{\partial \theta}\right]-\left(\frac{\pi}{2}\right)^{1 / 2} \mathrm{v}_{\mathrm{T} \alpha}\left|\nabla_{\|}^{(0)}\right| \tilde{\mathrm{V}}_{\| \alpha}-\frac{\mathrm{v}_{\tau \alpha}^{2}}{\mathrm{n}_{0 \alpha}} \nabla_{\|}^{(0)} \tilde{\mathrm{n}}_{\alpha}
\end{aligned}
$$

Here $\mathrm{L}_{\mathrm{n} \alpha}^{-1}=\mathrm{n}_{0 \alpha}^{-1} \mathrm{dn}_{0 \alpha} / \mathrm{dr}$; also, $\mathrm{n}_{0 \alpha}, \mathrm{T}_{0 \alpha}, \mathrm{M}_{\alpha}, \Omega_{c \alpha}, \mathrm{q}_{\alpha}$, and $\mathrm{v}_{\mathrm{T \alpha}}$ are the fast ion density, temperature, mass, cyclotron frequency, charge, and thermal velocity, respectively. The Landau resonance arises from the third term on the right-hand side of equation (4). This system of equations is solved as an initial value problem for the $3-D$ mode structure in a straight field line coordinate system based on a toroidal, finite $\beta$ equilibrium.

\section{Toroidal Alfvén Instabilities}

TAE instabilities occur in the gaps induced by toroidicity when two adjacent cylindrical shear Alfvén continua cross [3]; they involve the coupling of at least two poloidal harmonics and have been driven in tokamaks both by neutral beams [4-5] and ICRF produced tails [6]. We also predict TAE's to be accessible in moderate shear stellarators (e.g., ATF) and in low shear stellarators above a minimum toroidal mode number (e.g., $\mathrm{n} \geq 3$ in W7-AS); however, none have yet been observed. An important topic currently under investigation is whether Alfvén instabilities can be driven by alpha populations in the DT phase of TFTR [7]. In Fig. 1 we show growth rates vs. the peak $\beta_{\alpha}$ for $\mathbf{n}=2,3$ and 4 TAE instabilities in a typical TFTR DT supershot (dashed curves, \#76770). As can be seen, the thresholds are significantly above the achieved values of $\beta_{\alpha}(0)$. This is consistent with experimental observations showing a lack of any new TAE activity in DT operation $[7,8]$. One possible way to enhance the accessibility of alpha-driven TAE's is through increasing the $q(0)$ value. This moves the radial location of the TAE gaps inward, and aligns them more closely with the location of the maximum alpha pressure gradient. The effect of such profile changes is shown by the solid curves in Fig. 1 where MSE-measured $q$ profiles [9] of an enhanced $q(0)$ TFTR case ( $\$ 75963)$ are used. Higher growth rates and lower $\beta_{\alpha}(0)$ thresholds are obtained which fall within the $\beta_{\alpha}$ range already achieved in TFTR. Such techniques for destabilizing TAE's in the central region of a tokamak can also be of interest in future ignited devices for ash removal through q-profile control. An alternate way to lower TAE thresholds is to lower the ion temperature, thus decreasing ion Landau damping. In Fig. 2 predicted TAE thresholds and achieved $\beta_{\alpha}(0)$ 's are shown for a TFTR discharge ( $\# 75932$ ) where a helium-puff was used in order to transiently cool the ions. However, as indicated, the achieved $\beta_{\alpha}(0)$ remained subcritical for driving TAE instabilities. 


\section{Global Alfvén Instabilities}

Global Alfvén instabilities exist as discrete roots below minima in the shear Alfvén continua ; they tend to be dominated by a single poloidal mode number and have a global mode structure. Our model predicts that GAE modes may be excited in tokamaks which have central, slightly negative low shear regions. An example is shown in Fig. 3 for TFTR parameters. Such modes may become especially likely in devices such as TPX and ITER where significant bootstrap currents can create weak negative shear regions which will be in the same location as the maximum pressure gradient in the fast ion population.

GAE modes have been observed in the W7AS stellarator experiment [10] which operates with low values of magnetic shear. Their phase velocity is somewhat lower than the TAE mode, allowing them to be excited for $\left\langle v_{\text {beam }}\right\rangle / v_{A}(0)=0.15$ to 0.4 . Also, they are slightly off-resonant with the equilibrium magnetic field helicity $(\mathrm{k} \| \neq 0)$. Even though the ideal MHD, $\beta=0$ gaps close off as rational iotas enter the plasma, we observe peaks in the growth rates and minima in the real frequencies near rational iota values (Fig. 4); this is due to a discretization of the contunuum by the nonideal effects included in our model (i.e., ion FLR, resistivity, etc.) and the effect of the finite fast ion pressure. Since the instability also persists away from the rational iota values, it cannot be avoided simply by keeping iota in between the low order rationals. In W7AS the GAE instability is observed to disappear at high $\beta$; the gyrofluid model indicates a possible cause for this stabilization is the increased shear in the iota profile with increasing $\beta$, with somewhat lesser effects coming from increased Landau damping on the ambient plasma. An important issue for future higher shear, higher $\beta$ stellarators is whether there will be a stable window between the disappearance of the GAE (due to increasing shear) and the onset of the TAE instability.

\section{Nonlinear TAE/GAE Behavior}

The nonlinear gyrofluid model has been applied to TAE and GAE instabilities on both TFTR and W7-AS. A Fourier analysis of the simulated edge magnetic fluctuations has been compared with experiments and shows reasonably good agreement with measured spectra. An example of such a time-evolving frequency spectrum for TFTR parameters is shown in Fig. 5. The spectra are typically dominated by a peak at the main TAE frequency with higher harmonic peaks generated nonlinearly as the instability saturates. In the early stages of the nonlinear evolution, the mode number spectrum is dominated by the toroidal mode numbers with the highest growth rates; as a saturated state is reached, the nonlinearly generated $n=0$ component typically dominates. This component results in profile modifications and $\vec{E} \times \vec{B}$ flow velocities. The saturation mechanisms have been analyzed [2], indicating that sheared velocity flow amplification and q-profile modification (through magnetic island formation) are the essential components necessary to achieve a saturated nonlinear state. This suggests a possible way of controlling the TAE using RF generated flows [11].

\section{Conclusions}

A gyrofluid model using Landau closure has proven to be a powerful technique for analyzing fast ion destabilized shear Alfvén instabilities such as the TAE and GAE. Applying this both to tokamaks and the low shear stellerator W7-AS we find that both types of modes can exist in either device under the appropriate conditions. The model has predicted that the typical TFTR DT supershot should be below the $\beta_{\alpha}$ threshold for alpha-driven TAE instabilities, but if q-profiles with higher q $(0)$ 's can be generated, this threshold can be substantially reduced into a range of $\beta_{\alpha}$ that has been 
realized experimentally. Finally, the gyrofluid model has indicated that the TAE can achieve nonlinear saturation through mechanisms such as amplification of sheared flow velocities and quasilinear modification of the q-profile. 


\section{Acknowledgements}

We would like to express our thanks to both the TFTR and W7-AS experimental and modeling groups for providing access to profile data we have used in our calculations. This research was sponsored by the Office of Fusion Energy, U.S. Department of Energy, under contract DE-AC05-84OR21400 with Martin Marietta Energy Systems, Inc.

\section{References:}

[1] D. A. SPONG, B. A. CARRERAS, C. L. HEDRICK, Phys. Fl. B 4, 3316 (1992).

[2] D. A. SPONG, B. A. CARRERAS, C. L. HEDRICK, Phys. Plasmas 1 (5), 1994.

[3] C. Z. CHENG, L. CHEN, AND M. S. CHANCE, Ann. Phys. 161, 21 (1985); C. Z. Cheng and M. S. Chance, Phys. Fluids 29, 3695 (1986); G. Y. Fu and J. W. Van Dam, Phys. Fluids B 1, 1949 (1989).

[4] K. L. WONG, R. J. FONCK, S. F. PAUL, D. R. ROBERTS, E. D. FREDRICKSON, R. NAZIKIAN, H. K. PARK, M. BELL, N. L. BRETZ, R. BUDNY, S. COHEN, G. W. HAMMETT, F. C. JOBES, D. M. MEADE, S. S. MEDLEY, D. MUELLER, Y. NAGAYAMA, D. K. OWENS, AND E. J. SYNAKOWSKI, Phys. Rev. Lett. 66, 1874 (1991).

[5] W. W. HEIDBRINK, E. J. STRAIT, E. DOYLE, G. SAGER, AND R. SNIDER, Nuc. Fusion 31, 1635 (1992).

[6] J. R. WILSON, J. C. HOSEA, R. MAJESKI, C. K. PHILLIPS, J. H. ROGERS, G. SCHILLING, J. E. STEVENS, G. TAYLOR, AND THE TFTR GROUP, R. GOLDFINGER, D. J. HOFFMAN, M. MURAKAMI, D. RASMUSSEN, F. RIMINI, Bull. Am. Phys. Soc. 37, 1380 (1992).

[7] J. D. STRACHAN, et al., Phys. Rev. Lett. Vol. 72, No. 22, (3526) 1994.

[8] FREDERICKSON, E., et al., IAEA-CN-60/A-2-II-5, these Proceedings.

[9] LEVINTON, F., Princeton Plasma Physics Lab., personal communication (1994).

[10] A. WELLER, D. A. SPONG, R. JAENICKE, A. LAZAROS, F. P. PENNINGSFELD, S. SATTLER, W7-AS TEAM AND NBI GROUP, Phys. Rev. Lett. 72 (1220) 1994.

[11] G. G. CRADOCK, P. H. DIAMOND, M. ONO, H. BIGLARI, Phys. Plasmas 1, 1944 (1994). 


\section{Figure Captions}

Fig. 1 - Growth rates for TAE instabilities in a TFTR DT supershot vs. the central $\beta_{\alpha}$ value for a typical DT supershot with low $\mathrm{q}(0)$ (dashed curves) and for a higher $\mathrm{q}(0)$ case (solid curves). The shaded rectangular region represents the range of achieved central $\beta_{\alpha}{ }^{\prime}$ 's.

Fig. 2 - Time dependence of $\mathrm{n}=2,3$, and 4 TAE $\beta_{\alpha}$ thresholds along with the experimentally achieved $\beta_{\alpha}$ for a TFTR DT case where helium was in puff ed in to transiently cool the ions.

Fig. 3 - (a) two similar q-profiles in TFTR which result in (b) TAE and GAE instabilities.

Fig. 4 - Dependence of real frequencies (dashed curves) and growth rates (solid curves) of a $n=2$ GAE instability in W7-AS on the edge iota as the iota profile is uniformly changed (here $\tau_{\mathrm{Hp}}=\mathrm{R}_{0} / \mathrm{v}_{\mathrm{A}}(0)$ ).

Fig. 5 - Time evolving frequency spectrum of edge magnetic fluctuations in a nonlinear gyrofluid simulation of a TAE instability. 


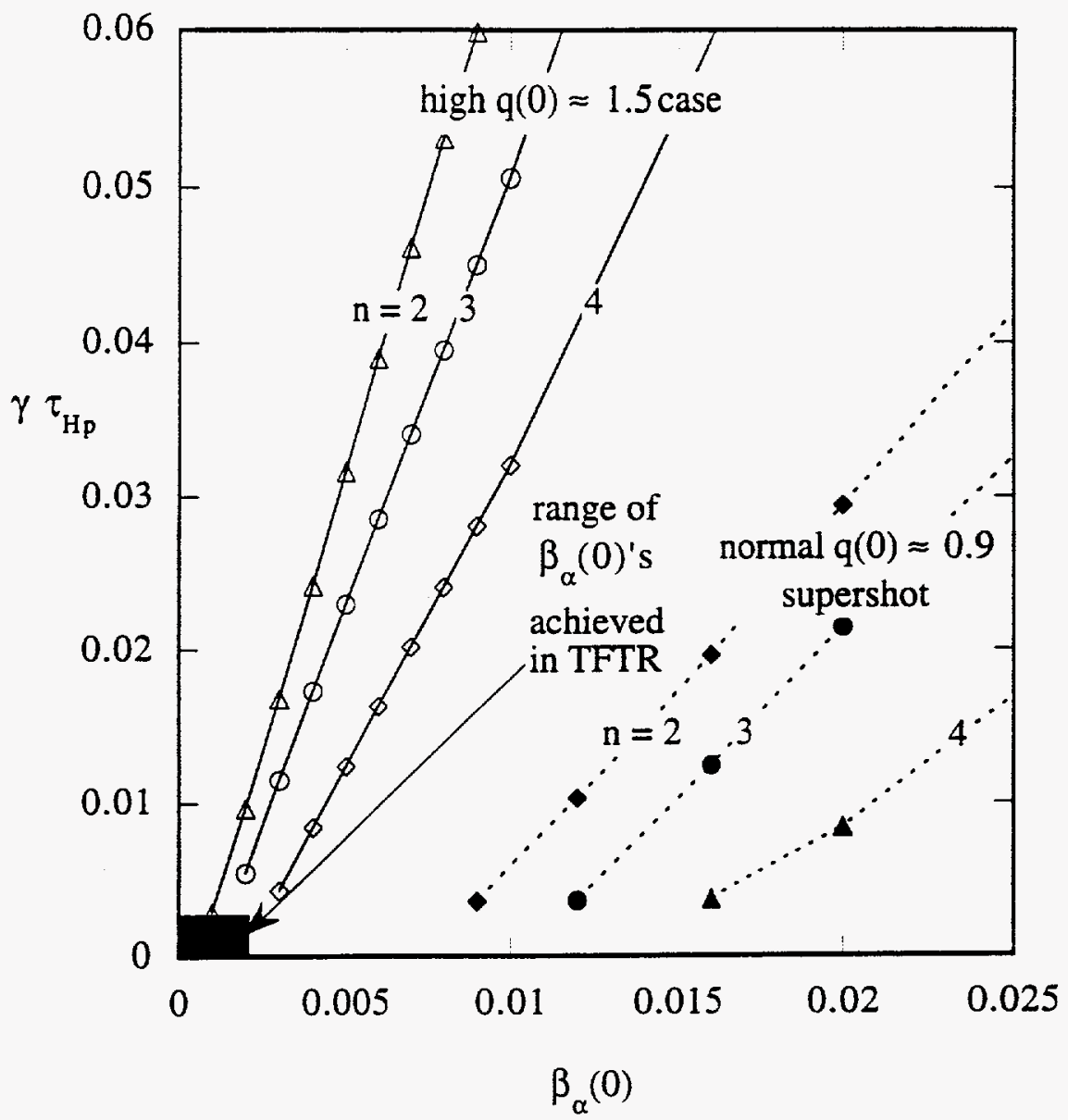

Figure 1 


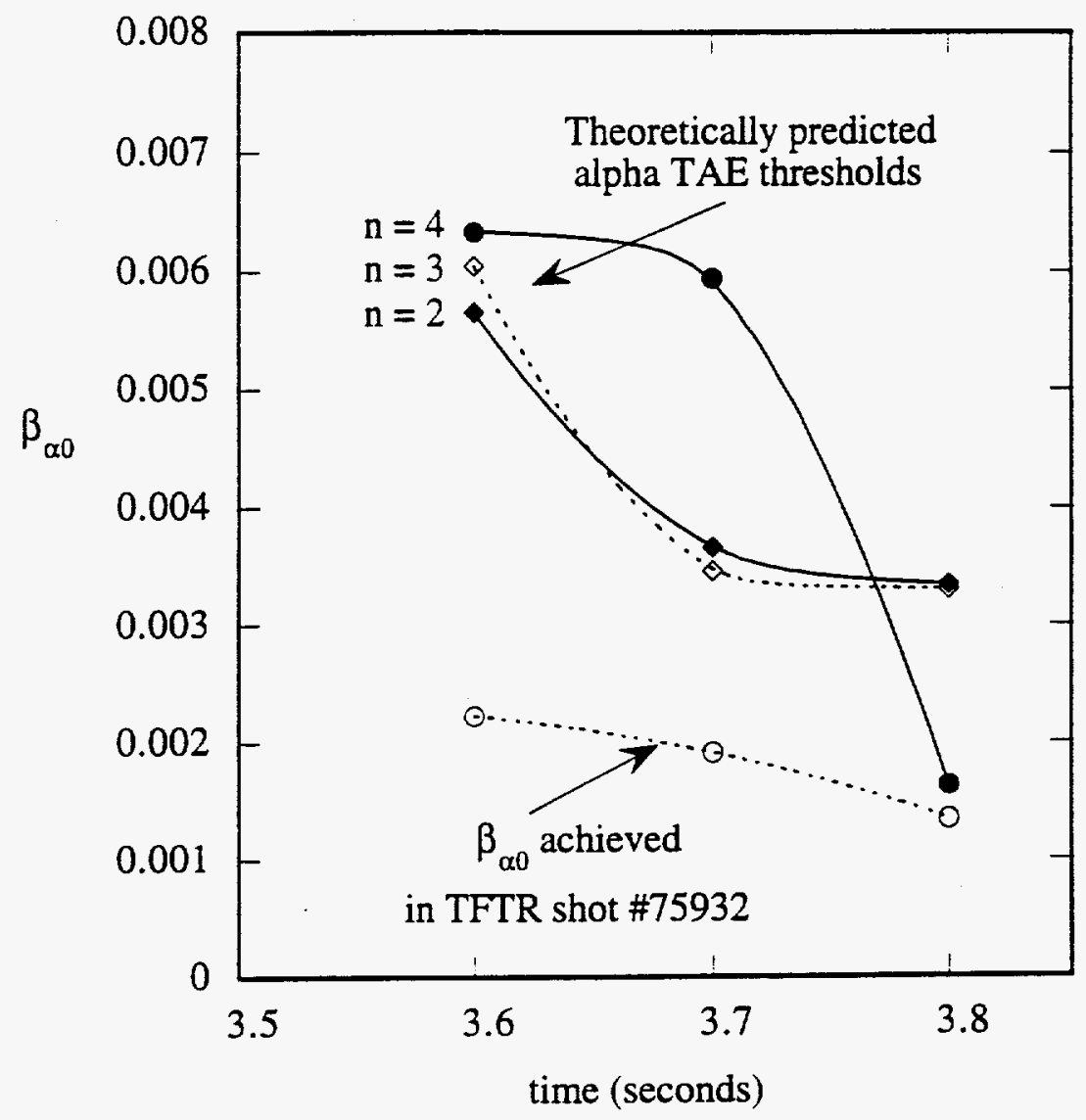

Figure 2 

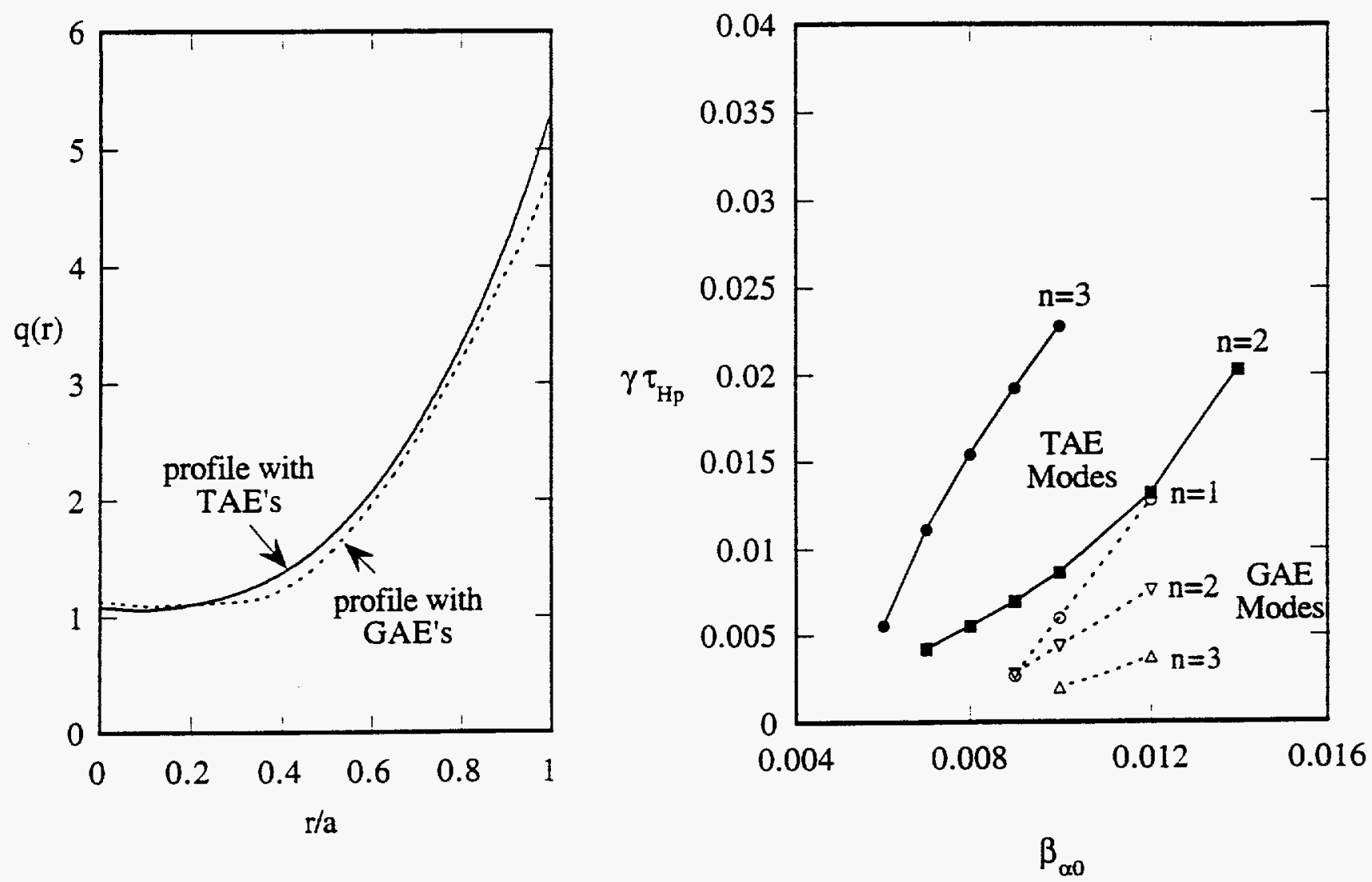

Figure 3 


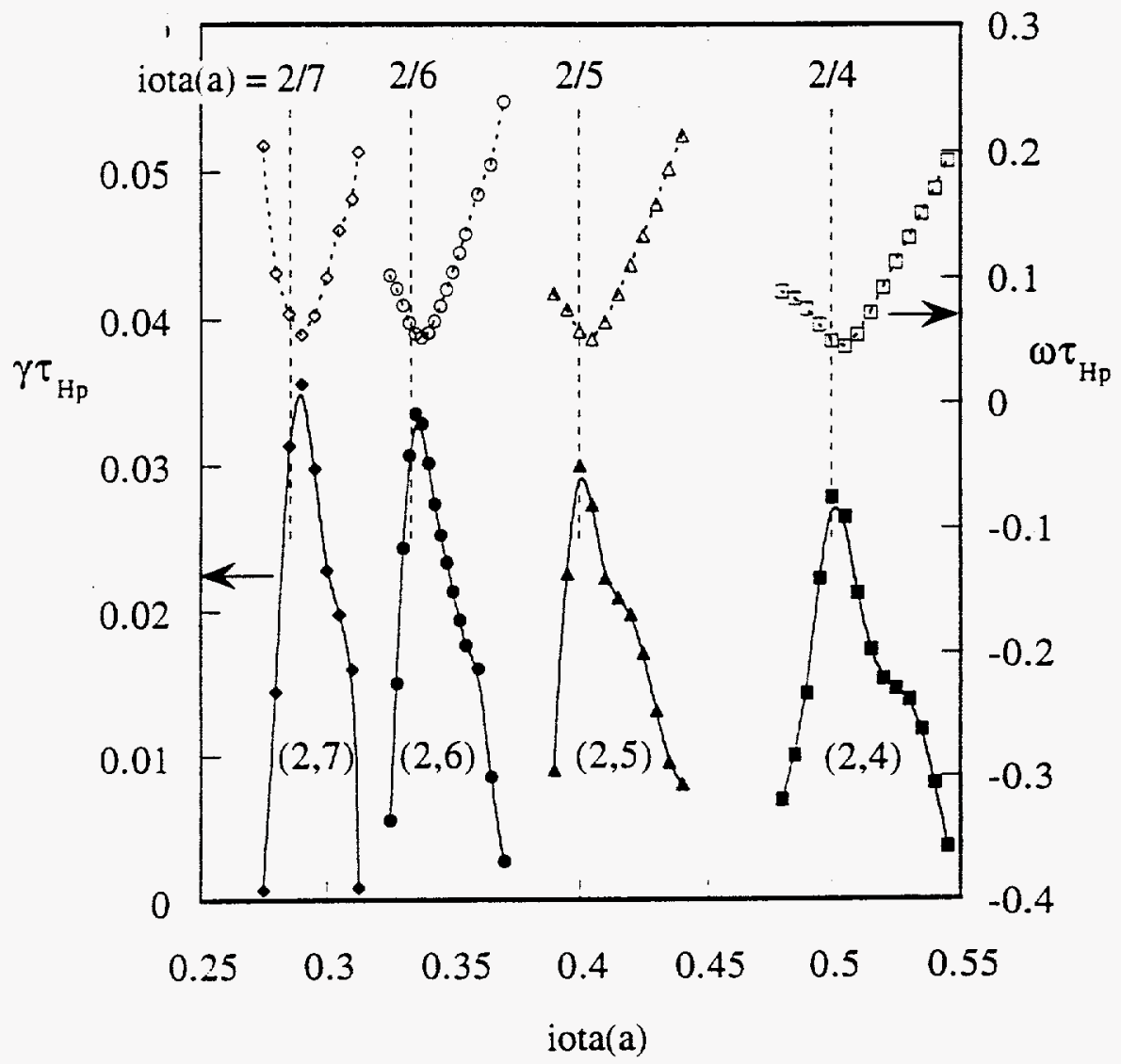

Figure 4 


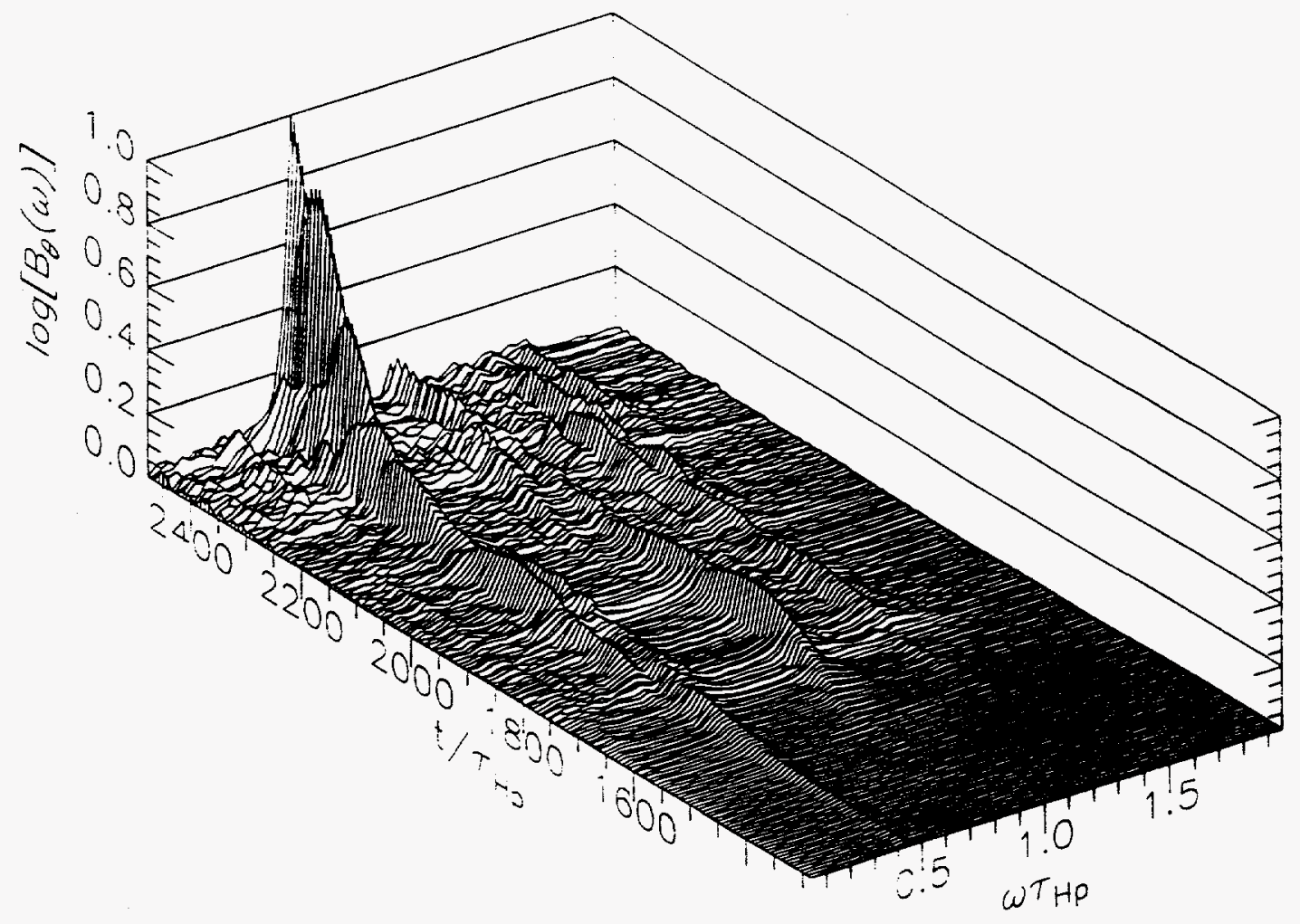

Figure 5 


\section{IAEA-CN-60/D-P-II-3}

\section{Energetic Particle Destabilization of Shear Alfvén Waves in Stellarators and Tokamaks}

D. A. Spong, B. A. Carreras, C. L Hedrick, J-N. Leboeuf Oak Ridge National Laboratory P. O. Box 2009, Oak Ridge, TN 37831-8071

A. Weller

Max-Planck-Institut für Plasmaphysik, IPP-EURATOMAssociation D-85748 Garching, Germany 


\section{Introduction and Motivations}

- Discrete Shear Alfvén modes exist within gaps of the ideal MHD continua (see next plot)

- Can be resonantly destabilized by fast ions

》 $\left(\omega / \mathbf{k}_{\text {III }}\right)_{\text {gap }} \approx \mathbf{v}_{\text {fast,ion }}$

" Fusion alphas, Neutral beam heating, RF Minority tails

- Resonant excitation $\rightarrow$ resonant loss

" unacceptable localized heat deposition on first wall

" lowered heating efficiency

- Alfvén instabilities are inherently damped

" Continuum absorption, ion/electron Landau, ion FLR, etc.

" Theoretical modeling/experiment can help identify stable regimes 


\section{Features of TAE/GAE Gyrofluid Model:}

- Non-perturbative approach

- Inherently includes continuum damping and multiple gap structures

- Other damping included: ion/electron Landau, ion FLR, resistivity, electron collisional effects

- Calculates global radial structure - sensitive to profile effects (uses TRANSP results)

- Applicable both linearly and nonlinearly 


\section{MAGNETIC FIELD GEOMETRIES:}

TFTR

W7-AS 


\section{TFTR Flux Surface with Magnetic Field Lines}

Color shading indicates TAE mode structure

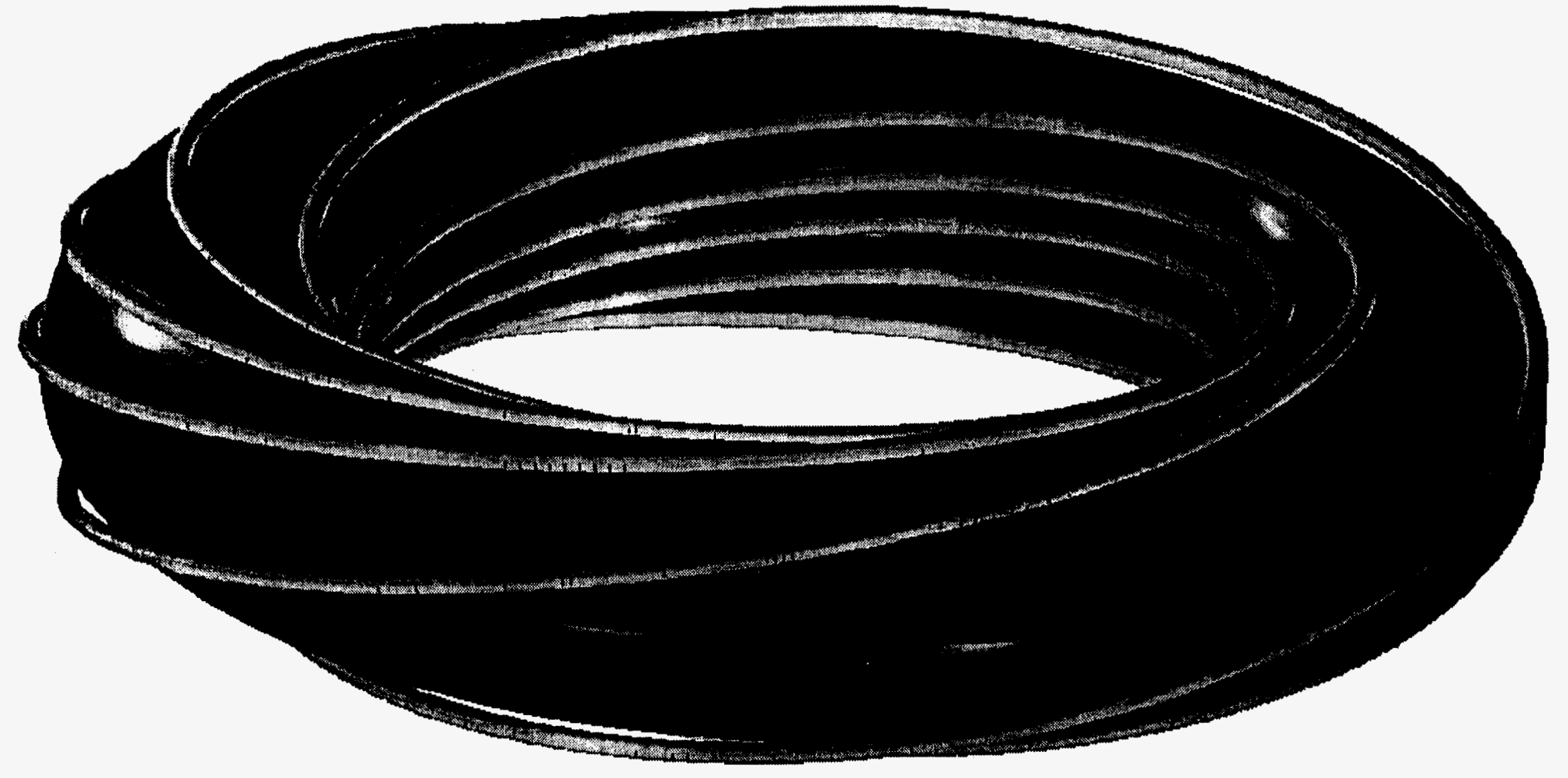




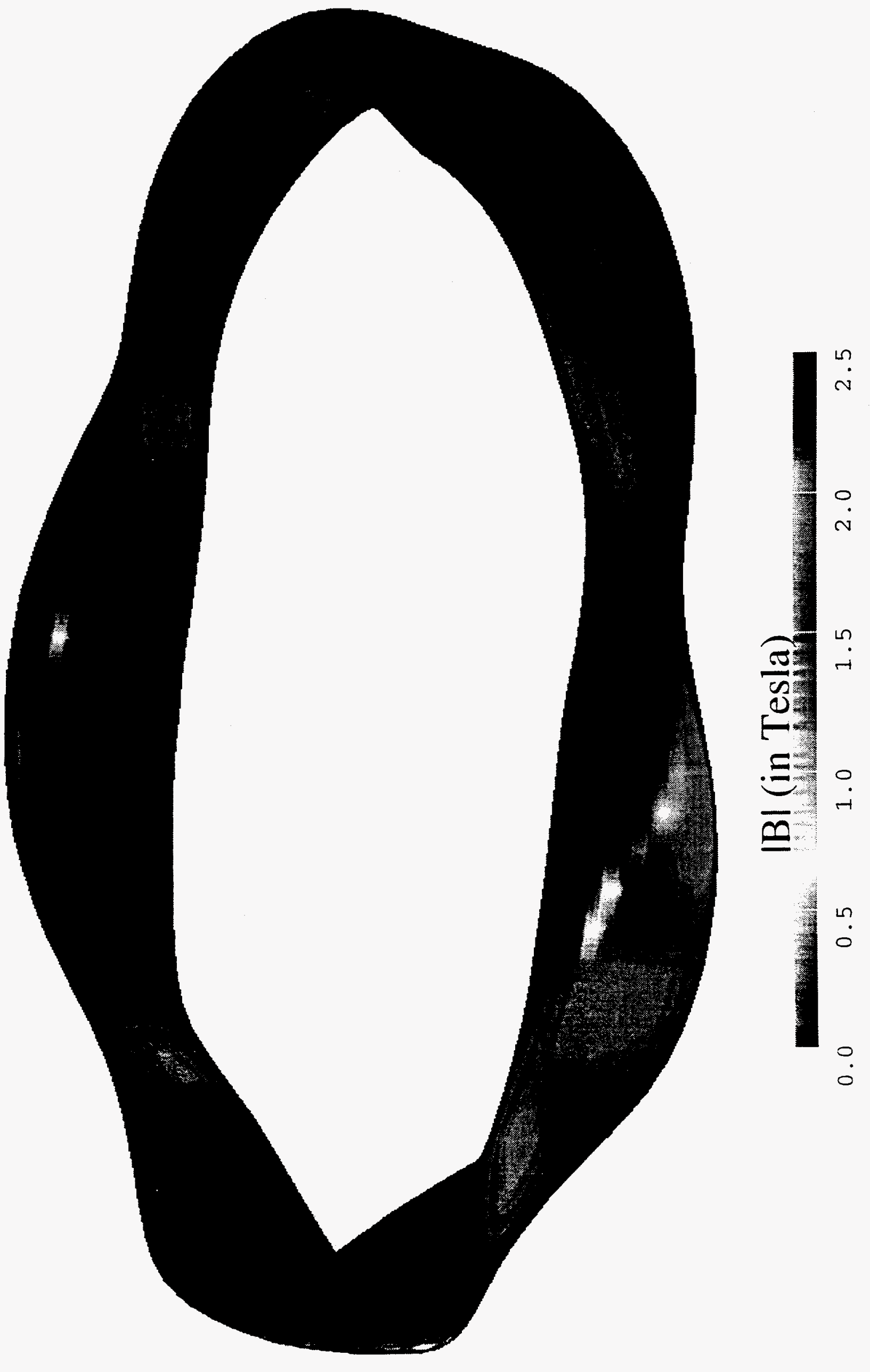




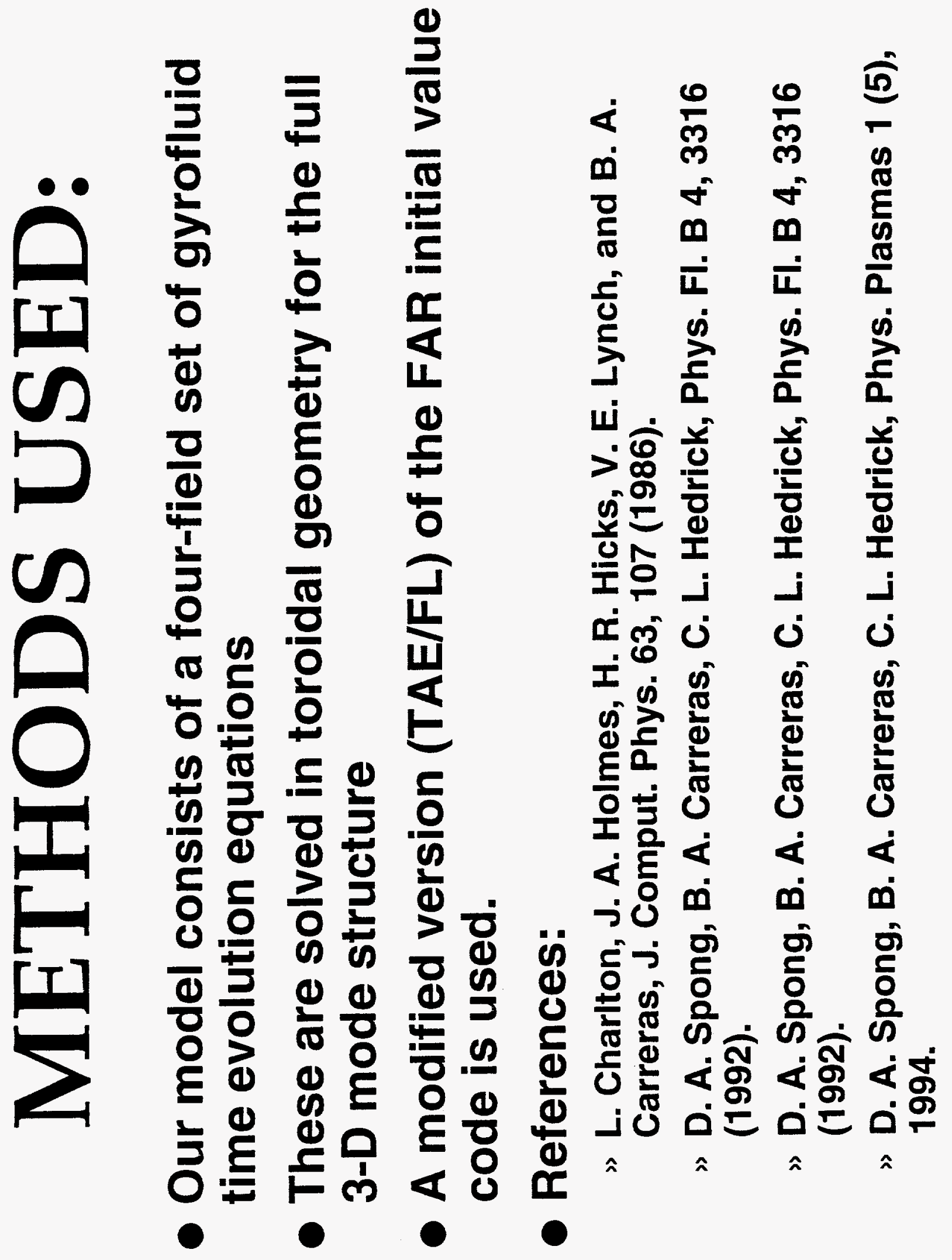




\section{(1) A generalized Ohm's law}

This includes: (a) the usual collisional resistivity and (b) a collisionless resistivity caused by incomplete cancellation of $E_{1 \mid}$ by the electrons for $k_{1 \mid} \neq 0$ modes at Alfvénic frequencies.

$$
\frac{\partial \tilde{\psi}}{\partial \mathrm{t}}=\vec{\nabla}_{\|} \tilde{\phi}+\frac{\mathrm{n}_{\mathrm{e}} \mathrm{e}^{2}}{\mathrm{~m}_{\mathrm{i}} \omega_{\mathrm{ci}}^{2}} \operatorname{Imag}\left(\eta_{\mathrm{G}}\right) \nabla_{\perp}^{2} \tilde{\psi}
$$

where $\eta_{\mathrm{G}}=\mathrm{i} \frac{\mathrm{k}_{\| 1}^{2} \mathrm{~T}_{\mathrm{e}}}{\omega \mathrm{n}_{\mathrm{e}} \mathrm{e}^{2}} \mathrm{R}_{\mathrm{ei}} ; \quad \mathrm{R}_{\mathrm{ei}}^{-1}=1+\frac{\mathrm{Y}_{0 \mathrm{e}}}{\mathrm{D}_{\mathrm{e}}}+\tau_{\mathrm{i}}^{-1}\left(1+\frac{\mathrm{Y}_{0 \mathrm{i}}}{\mathrm{D}_{\mathrm{i}}}\right) ; \quad \tau_{\mathrm{i}}=\frac{\mathrm{T}_{\mathrm{i}}}{\mathrm{T}_{\mathrm{e}}}$

$$
\mathrm{Y}_{0 \mathrm{j}}=\xi_{\mathrm{j}} \mathrm{Z}\left(\zeta_{\mathrm{j}}\right) ; \quad \mathrm{D}_{\mathrm{j}}=1+\frac{\mathrm{i} v_{\mathrm{j}}}{\omega} \mathrm{Y}_{0 \mathrm{j}} ; \quad \xi_{\mathrm{j}}=\frac{\omega}{\sqrt{2} \mathrm{k}_{\mathrm{ll}} \mathrm{v}_{\mathrm{th}, \mathrm{j}}} ; \quad \zeta_{\mathrm{j}}=\frac{\omega+\mathrm{i} v_{\mathrm{j}}}{\omega} \xi_{\mathrm{j}}
$$

Asymptotic limits:

$$
\frac{\mathrm{n}_{\mathrm{e}} \mathrm{e}^{2}}{\mathrm{~m}_{\mathrm{i}} \omega_{\mathrm{ci}}^{2}} \operatorname{Imag} .\left(\eta_{\mathrm{G}}\right)= \begin{cases}\left(\sqrt{\frac{\pi}{2}} \frac{\rho_{\text {ion }}^{2}}{\tau_{\mathrm{i}}} \frac{\mathrm{v}_{\mathrm{A}}^{2}}{v_{\text {th, }}^{2}}\left|\nabla_{\mathrm{H}}\right|\right) & \text { for } v_{\mathrm{e}} / \omega<1 \\ \left(\frac{\mathrm{m}_{\mathrm{e}} v_{\mathrm{e}}}{2 \mathrm{n}_{\mathrm{e}} \mathrm{e}^{2}}\right) & \text { for } v_{\mathrm{e}} / \omega \gg>1\end{cases}
$$




\section{(2) Toroidal component of vorticity includes electron and ion Landau damping (with collisional effects) and ion FLR:}

$$
\frac{\partial \mathrm{U}}{\partial t}=-\overrightarrow{\mathrm{v}}_{\perp} \cdot \vec{\nabla} \mathrm{U}-\vec{\nabla}_{\mathrm{U}}\left(\frac{\tilde{\mathrm{J}}_{\varphi}+\mathrm{J}_{\varphi, \mathrm{eq}}}{\mathrm{B}_{\varphi}}\right)+\left[\hat{\mathrm{e}}_{\varphi} \times \vec{\nabla}\left(\frac{\mathrm{R}}{\mathrm{B}_{\varphi}}\right)\right] \cdot \vec{\nabla} \tilde{\mathrm{p}}_{\alpha}+\omega_{\text {real }} \rho_{\mathrm{i}}^{2} \nabla_{\perp}^{2} \mathrm{U}-\frac{\mathrm{c}^{2} \beta_{\text {avg }} \operatorname{Imag}\left(\mathrm{S}_{\mathrm{ei}}\right)}{8 \pi \omega_{\text {real }}} \Omega_{\mathrm{d}}^{2}(\phi)
$$

where $\mathrm{S}_{\mathrm{ei}}=\mathrm{Y}_{2 \mathrm{e}}+\tau_{\mathrm{i}} \mathrm{Y}_{2 \mathrm{i}}-\mathrm{i} \frac{v_{\mathrm{e}}}{\omega} \frac{\mathrm{Y}_{1 \mathrm{e}}^{2}}{\mathrm{D}_{\mathrm{e}}}-\mathrm{i} \frac{v_{\mathrm{i}}}{\omega} \frac{\mathrm{Y}_{1 \mathrm{i}}^{2}}{\mathrm{D}_{\mathrm{i}}}+\mathrm{R}_{\mathrm{ie}}\left(\frac{\mathrm{Y}_{\mathrm{le}}}{\mathrm{D}_{\mathrm{e}}}-\frac{\mathrm{Y}_{\mathrm{ii}}}{\mathrm{D}_{\mathrm{i}}}\right)^{2}$

$$
\mathrm{Y}_{0 \mathrm{j}}=\xi_{\mathrm{j}} \mathrm{Z}\left(\zeta_{\mathrm{j}}\right) ; \quad \mathrm{Y}_{\mathrm{ij}}=\xi_{\mathrm{j}}\left[\zeta_{\mathrm{j}}+\left(\frac{1}{2}+\zeta_{\mathrm{j}}^{2}\right) \mathrm{Z}\left(\zeta_{\mathrm{j}}\right)\right]
$$$$
\mathrm{Y}_{2 \mathrm{j}}=\xi_{\mathrm{j}}\left[\frac{3}{2} \zeta_{\mathrm{j}}+\zeta_{\mathrm{j}}^{3}+\left(\frac{1}{2}+\zeta_{\mathrm{j}}^{2}+\zeta_{\mathrm{j}}^{4}\right) \mathrm{Z}\left(\zeta_{\mathrm{j}}\right)\right]
$$

$$
\xi_{\mathrm{j}}=\frac{\omega}{\sqrt{2} \mathrm{k}_{\| 1} \mathrm{v}_{\mathrm{th}, \mathrm{j}}} ; \quad \zeta_{\mathrm{j}}=\frac{\omega+\mathrm{i} v_{\mathrm{j}}}{\omega} \xi_{\mathrm{j}}
$$




\section{(3) Fast ion gyrofluid equations with Landau closure (two-pole approximation):}

$$
\begin{aligned}
& \frac{\partial \tilde{\mathrm{n}}_{\alpha}}{\partial \mathrm{t}}=\omega_{\mathrm{d} \alpha} \Omega_{\mathrm{l}}\left(\tilde{\mathrm{n}}_{\alpha}\right)-\mathrm{n}_{0 \alpha} \nabla_{\|}^{(0)} \tilde{\mathrm{v}}_{\| \alpha}+\mathrm{n}_{0 \alpha} \boldsymbol{\Omega}_{\mathrm{l}}(\phi)-\frac{\mathrm{dn}}{\mathrm{dr}} \frac{1}{\mathrm{r}} \frac{\partial \phi}{\partial \theta}+\overline{\mathrm{D}}_{\mathrm{p}_{\alpha}} \nabla_{\perp 0}^{2} \tilde{\mathrm{n}}_{\alpha} \\
& \frac{\partial \tilde{\mathrm{v}}_{\| \alpha}}{\partial \mathrm{t}}=\omega_{\mathrm{d} \alpha} \Omega_{\mathrm{l}}\left(\tilde{\mathrm{v}}_{\| \alpha}\right)-\left(\frac{\pi}{2}\right)^{1 / 2} \mathrm{v}_{\mathrm{th} \alpha}\left|\nabla_{\|}^{(0)}\right| \tilde{\mathrm{v}}_{\| \alpha}-\frac{\mathrm{v}_{\mathrm{th} \alpha}^{2}}{\mathrm{n}_{0 \alpha}} \nabla_{\|}^{(0)} \tilde{\mathrm{n}}_{\alpha}-\frac{\mathrm{v}_{\mathrm{th} \alpha}^{2}}{\mathrm{n}_{0 \alpha}} \frac{\mathrm{dn}}{\mathrm{dr}} \frac{1}{\mathrm{r}} \frac{\partial \psi}{\partial \theta}+\overline{\mathrm{D}}_{\mathrm{v}_{\| \alpha}} \nabla_{\perp 0}^{2} \tilde{\mathrm{v}}_{\| \alpha},
\end{aligned}
$$

where $\boldsymbol{\Omega}_{\mathrm{l}}$ is the operator:

$$
\begin{aligned}
& \Omega_{\mathrm{l}} \equiv \frac{\mathrm{R}^{2}}{2} \frac{\partial}{\partial \mathrm{r}}\left(\frac{1}{\mathrm{R}^{2}}\right) \frac{1}{\mathrm{r}} \frac{\partial}{\partial \theta}-\frac{\mathrm{R}^{2}}{2 \mathrm{r}} \frac{\partial}{\partial \theta}\left(\frac{1}{\mathrm{R}^{2}}\right) \frac{\partial}{\partial \mathrm{r}} \propto(\hat{\mathrm{b}} \times \nabla \mathrm{B}) \bullet \nabla, \\
& \omega_{\mathrm{c} \alpha}=\Omega_{\mathrm{c} \alpha} \tau_{\mathrm{Hp}}, \quad \mathrm{v}_{\mathrm{th} \alpha}=\left(\mathrm{T}_{0 \alpha} / \mathrm{M}_{\alpha}\right)^{1 / 2} / \mathrm{v}_{\mathrm{A}}(\mathrm{r}=0),
\end{aligned}
$$




\section{These equations are solved using the TAE/FL initial value code}

- Implicit linear/explicit nonlinear algorithm extension of FAR code (L. Charlton, et al., J. Comput. Phys. 63, 107 (1986))

- Linearly, all growing modes can be identified

- Accepts general noncircular tokamak equilibria uses straight field line coordinates

- 3-D mode structure is represented using Fourier expansions in $\zeta$ and $\theta$, finite difference grid in radius

$$
\mathrm{X}(\rho, \theta, \zeta)=\sum_{\mathrm{mn}}\left[\mathrm{X}_{\mathrm{mn}}^{(\mathrm{c})}(\rho) \cos (\mathrm{m} \theta+\mathrm{n} \zeta)+\mathrm{X}_{\mathrm{mn}}^{(\mathrm{s})}(\rho) \sin (\mathrm{m} \theta+\mathrm{n} \zeta)\right]
$$

- Iteration scheme:

$$
L \frac{\partial}{\partial \mathrm{t}} \overrightarrow{\mathrm{X}}=R \overrightarrow{\mathrm{X}} \quad \Rightarrow \quad \overrightarrow{\mathrm{X}}^{\mathrm{n}+1}=\left[L-\frac{\Delta t}{2} R\right]^{-1}\left[L+\frac{\Delta t}{2} R\right] \overrightarrow{\mathrm{X}}^{\mathrm{n}}
$$


O
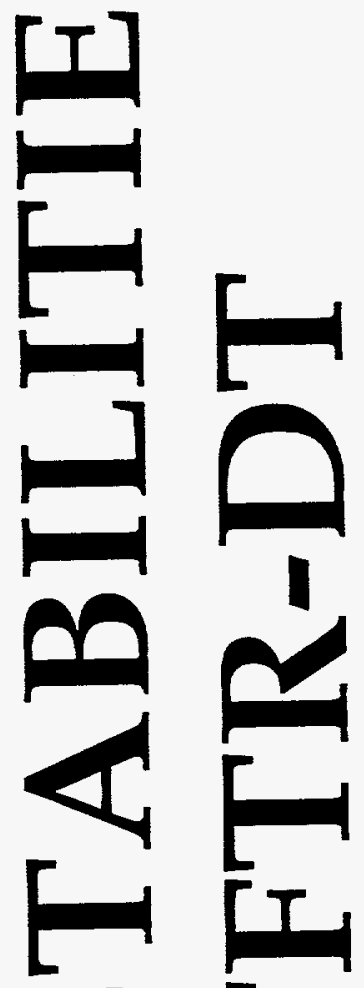

$\omega E$

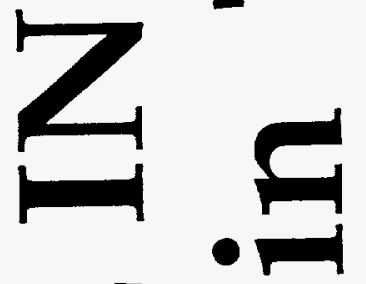

[I]
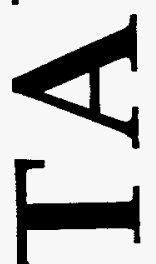


\section{Lower instability thresholds are required to observe alpha-driven TAE's in TFTR.}

- Alphas are relatively dilute: $\beta_{\alpha}(0) \leq 0.003$

》 Compare to $\beta(0)$ of beams and RF tails of $\approx 0.01$

- Minimization of TAE damping

"Decrease $T_{\text {ion }}$ to lower ion Landau damping

"Vary $q(r), n_{\text {ion }}(r)$ to lower continuum damping

- Enhancement of TAE instability drive

" Increase $q(0)$ in order to align TAE gap structure with peak alpha pressure gradient

》Vary $v_{\alpha} / v_{A}$ to obtain stronger resonance coupling 


\section{Lowering $\mathrm{T}_{\text {ion }}$ decreases TAE thresholds}
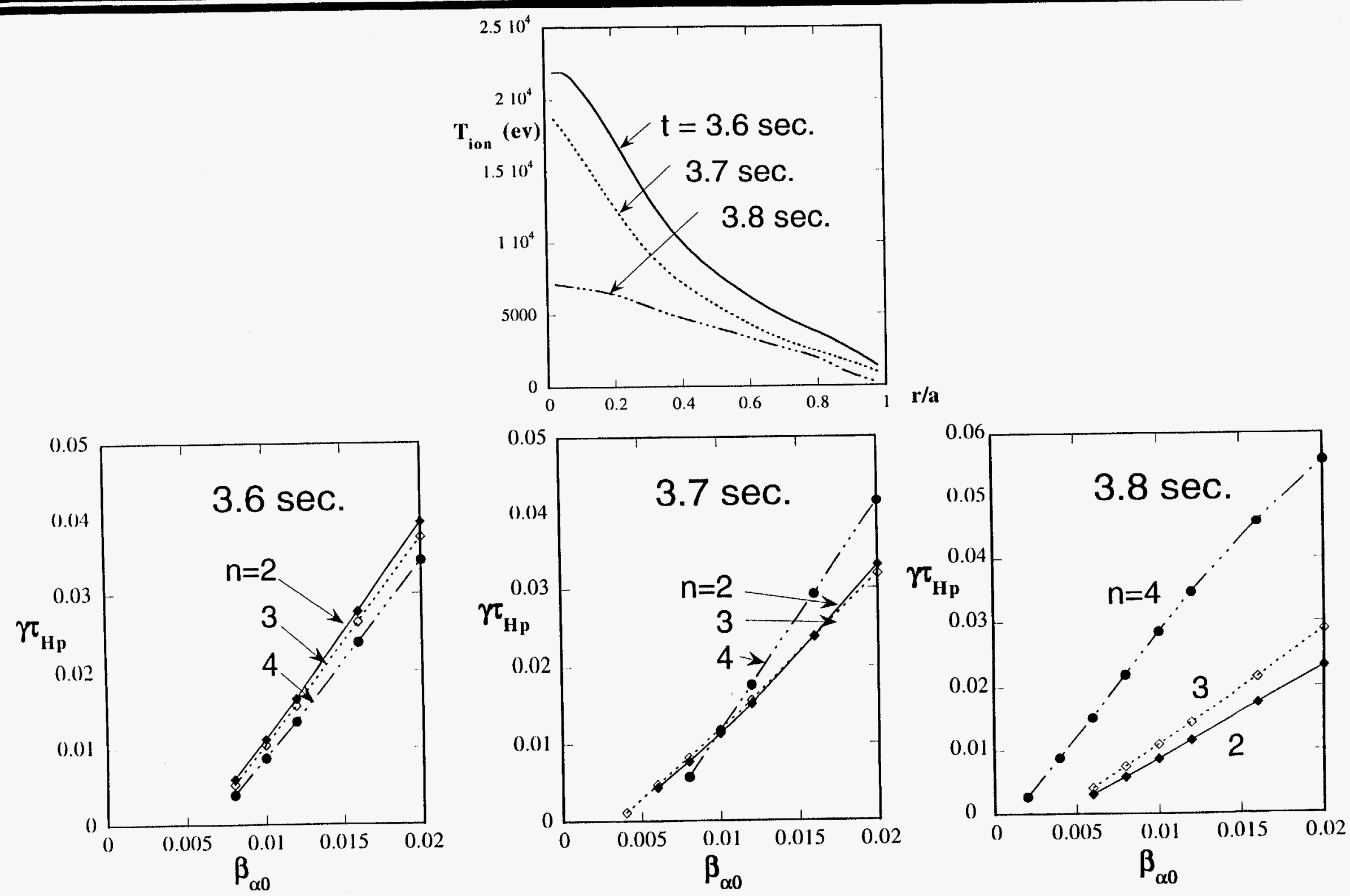


\section{With lower $\mathrm{T}_{\text {ion }}$, the alpha-driven TAE threshold is reduced, but the achieved $\beta_{\alpha}$ also decreases in time:}

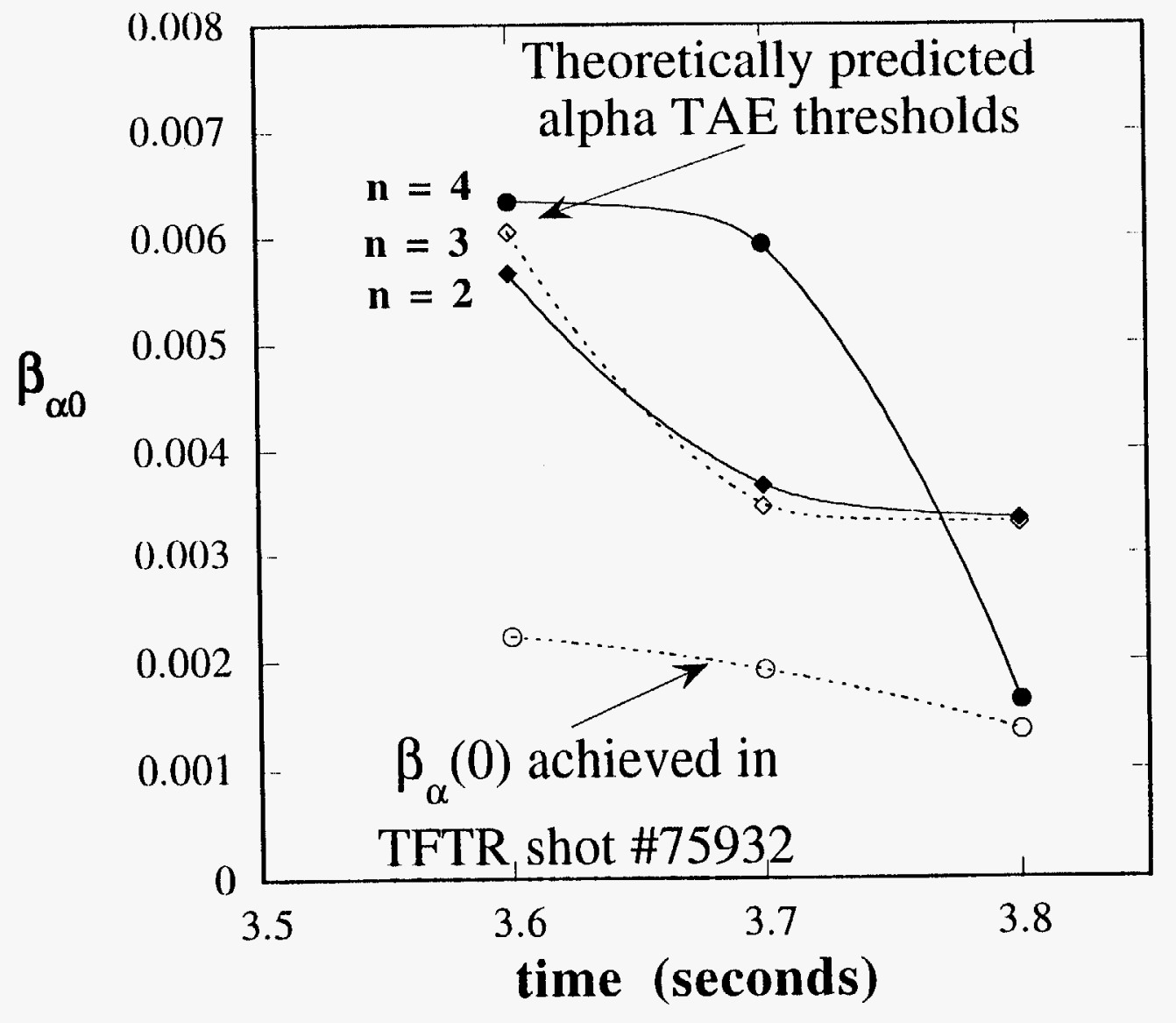




\section{With increasing $q(0)$ the TAE gap locations move inward, becoming more aligned with the peak in $d p_{\alpha} / d r$.}

$\mathbf{n}=\mathbf{2}$

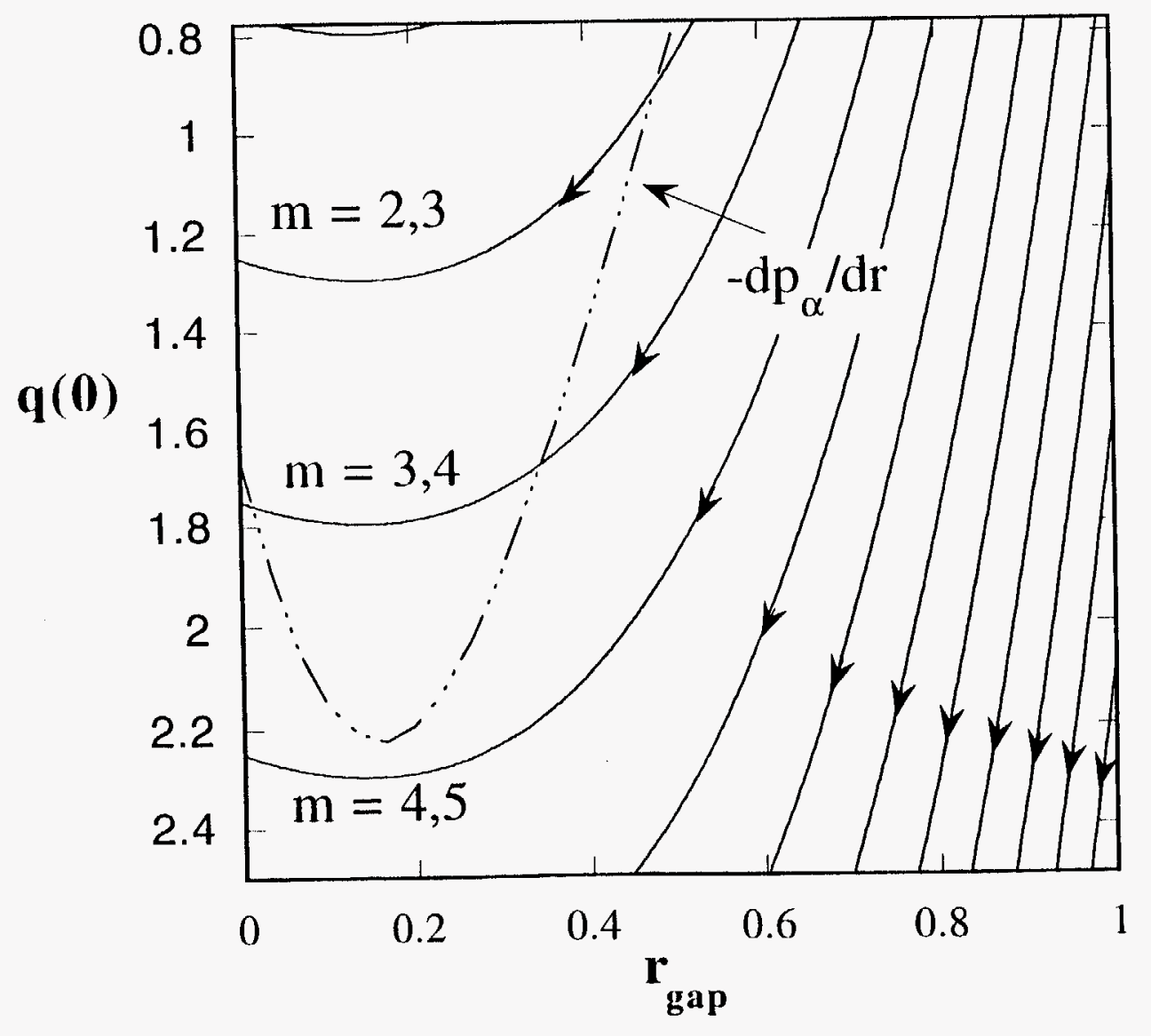


TFTR has obtained high $q(0)$ cases in DD which would lead to lowered $\alpha$ TAE thresholds in DT. ${ }^{r_{\mathrm{Hp}}^{0.04}}{ }_{0.03}^{0.03}$ MSE measured q profile evolution in shot\#75963 (from Fred Levinton)

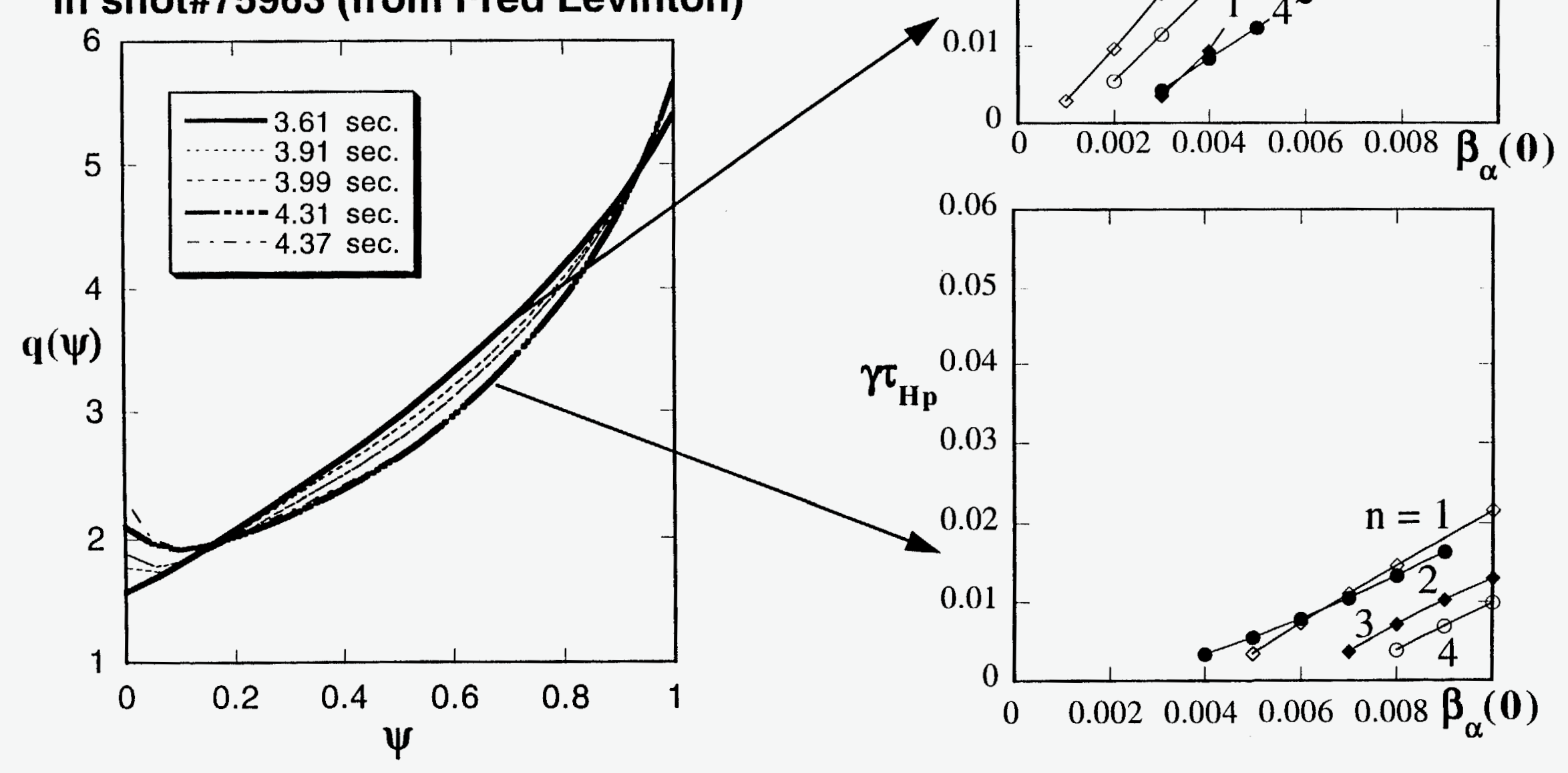




\section{Comparison of a high $q(0)$ TFTR case (\#75963) with a typical supershot (\#76770) shows significantly lowered TAE thresholds:}

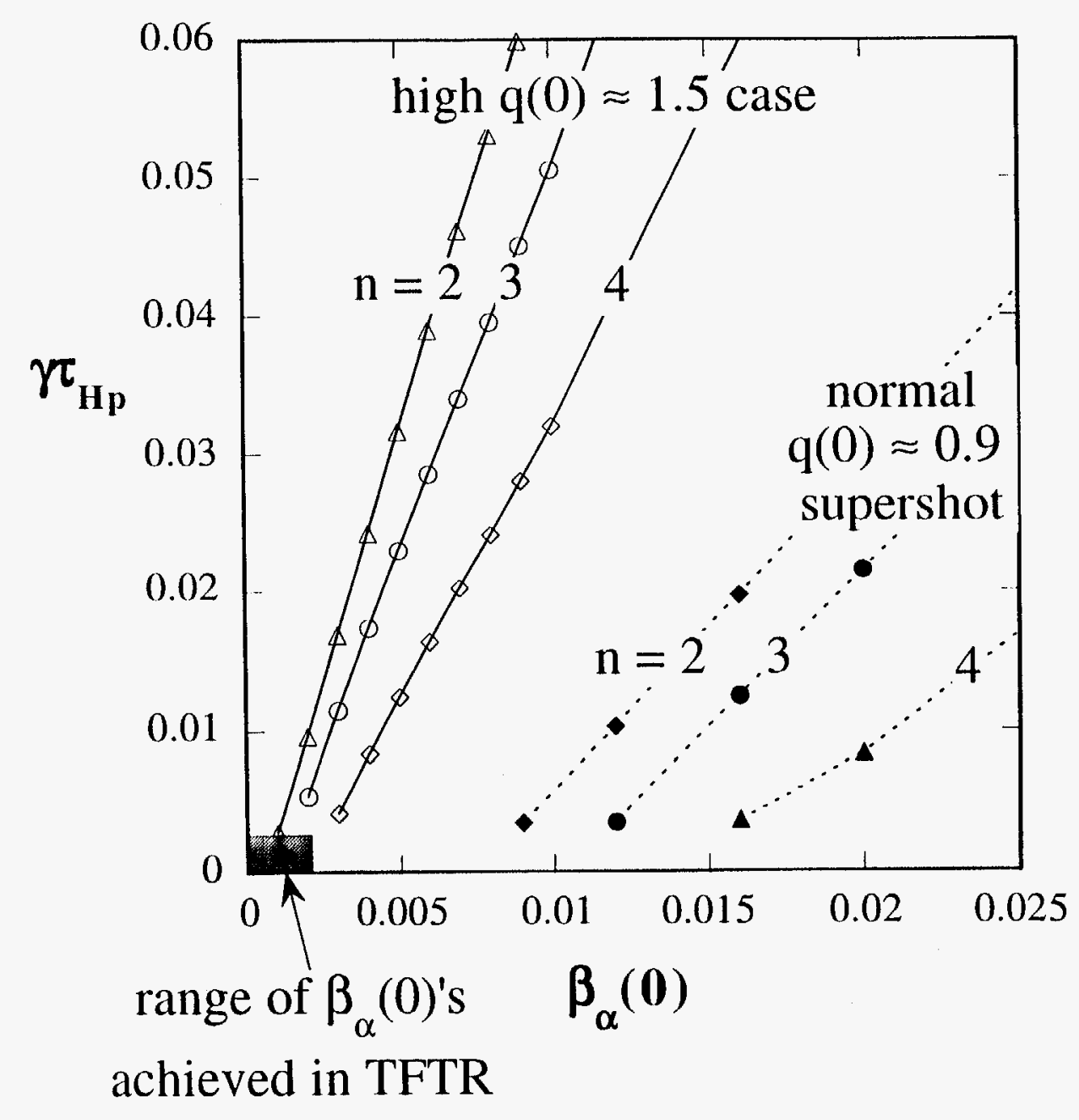




\section{GAE INSTABILITIES in TOKAMAKS}




\section{With sufficiently flat q-profiles, tokamaks (TFTR) can also be unstable to \\ GAE instabilities.}
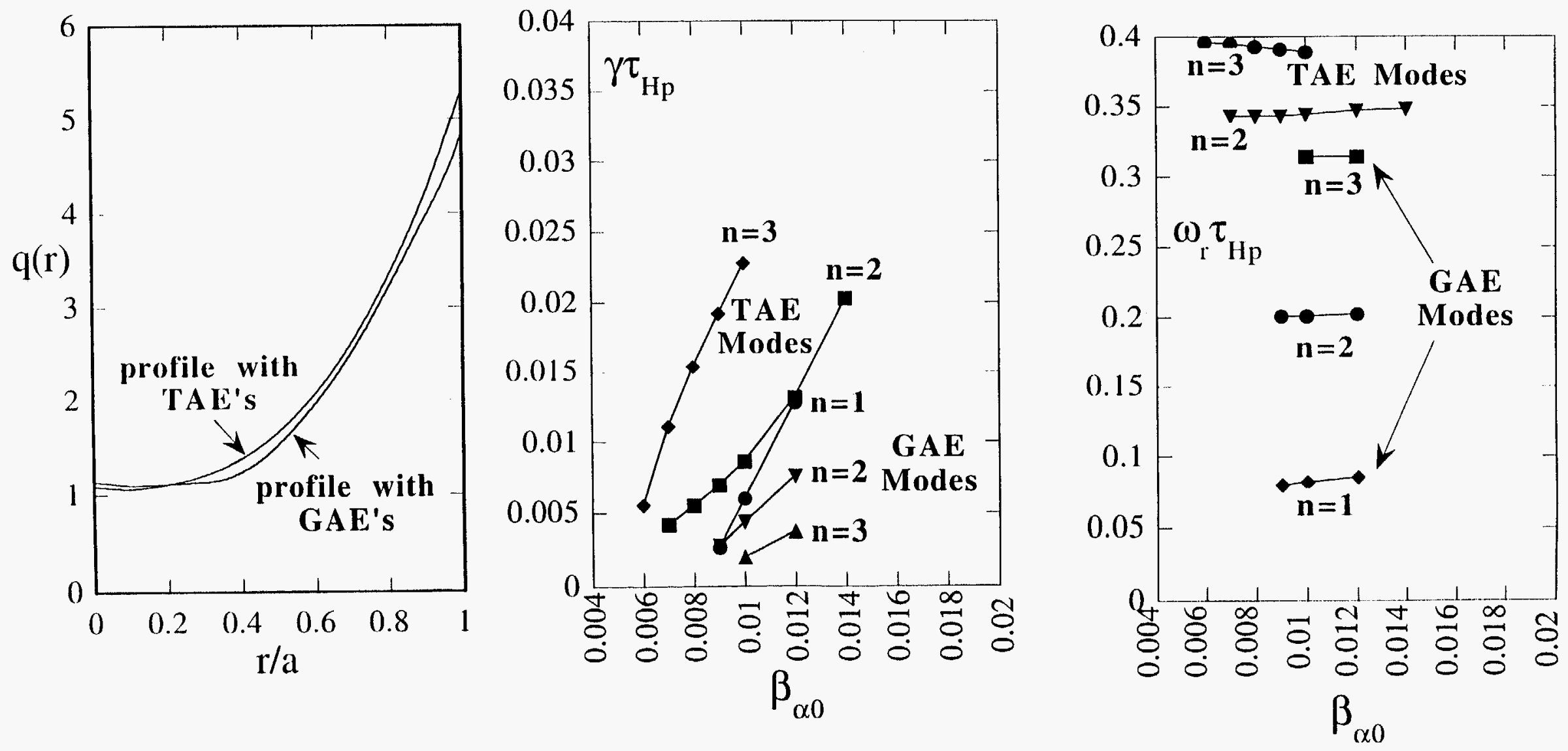


\section{TAE density fluctuations should show more of a ballooning signature than those of the GAE:}
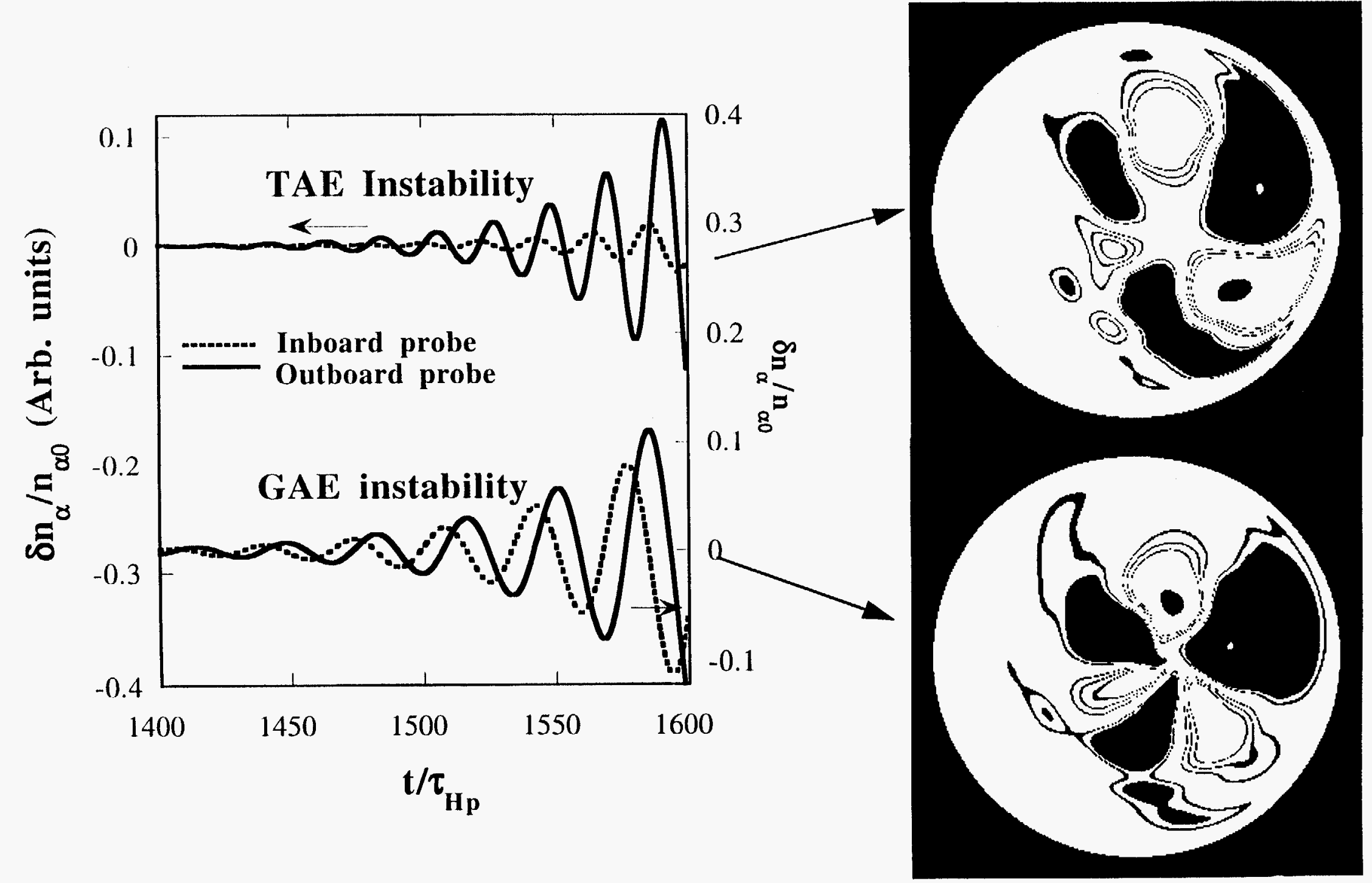


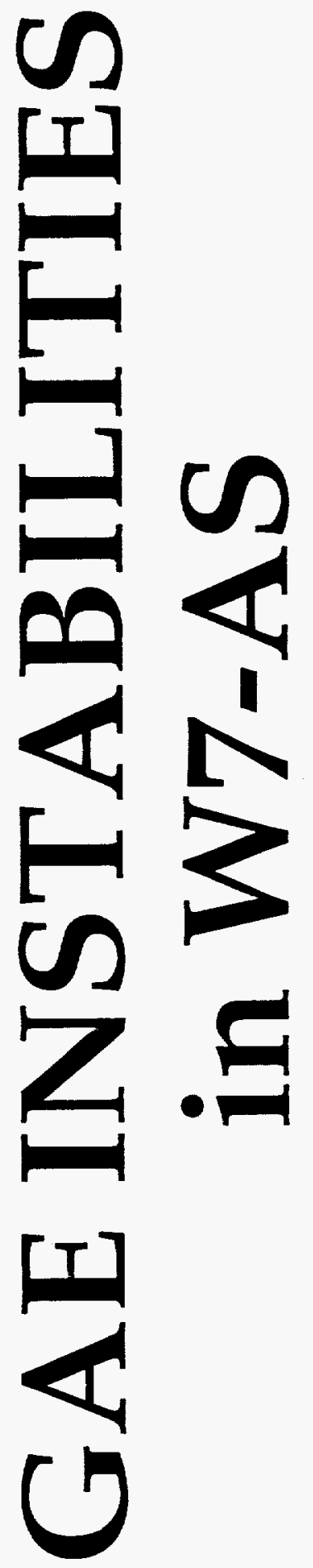




\section{Global Alfvén Stability Issues in W7AS}

- Profile, parameter sensitivities
》 $v_{\text {beam }} / v_{A}, p_{\text {beam }}(r), f_{\text {beam }}(E), \beta_{\text {beam }}$
" iota(r), d(iota)/dr

- What causes the GAE to appear/disappear?

- Relation between GAE and TAE modes

"TAE's become possible at higher $n$ 's, $v_{\text {fast }} / v_{A}$, shear

»TAE's may be more relevant to $\alpha$ 's in stellarators

- How does one extend present GAE observations/physics to future devices?

»Do GAE instabilities provide a means for ash removal?

»With somewhat larger shear will there be a stability window between the GAE and TAE modes? 


\section{For a typical W7AS low shear, iota $>1 / 3$ profile, only the GAE is present at low $n(=1,2)$. However, for $\mathrm{n} \geq 3$ both TAE and GAE modes coexist.}

»For a TAE root to exist, there must be enough variation in $q(r)$ such that

$$
\mathbf{k}_{\mathrm{II}, \mathrm{m}}=-\mathbf{k}_{\mathrm{ll}, \mathrm{m}+1} \text { or } \mathrm{q}(\mathrm{r})=(2 \mathrm{~m}+1) / 2 \mathrm{n}
$$

"With a q-profile of the form: $q(r)=m / n+\delta q$, this implies that $\delta q \geq 1 / 2 n$

》As $n$ increases TAE roots become accessible.

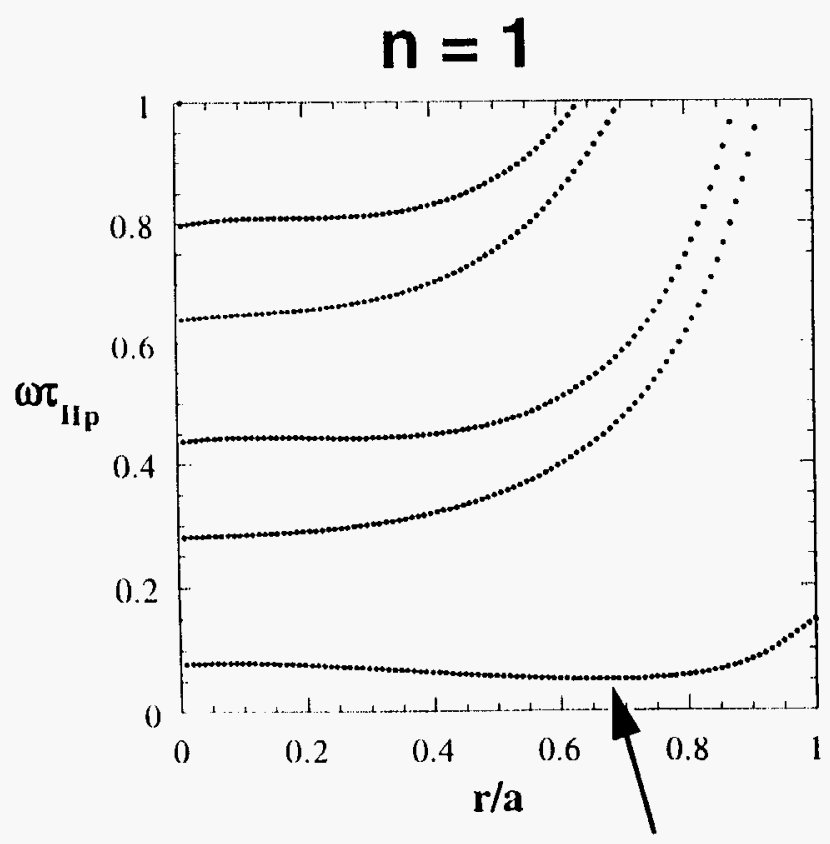

GAE

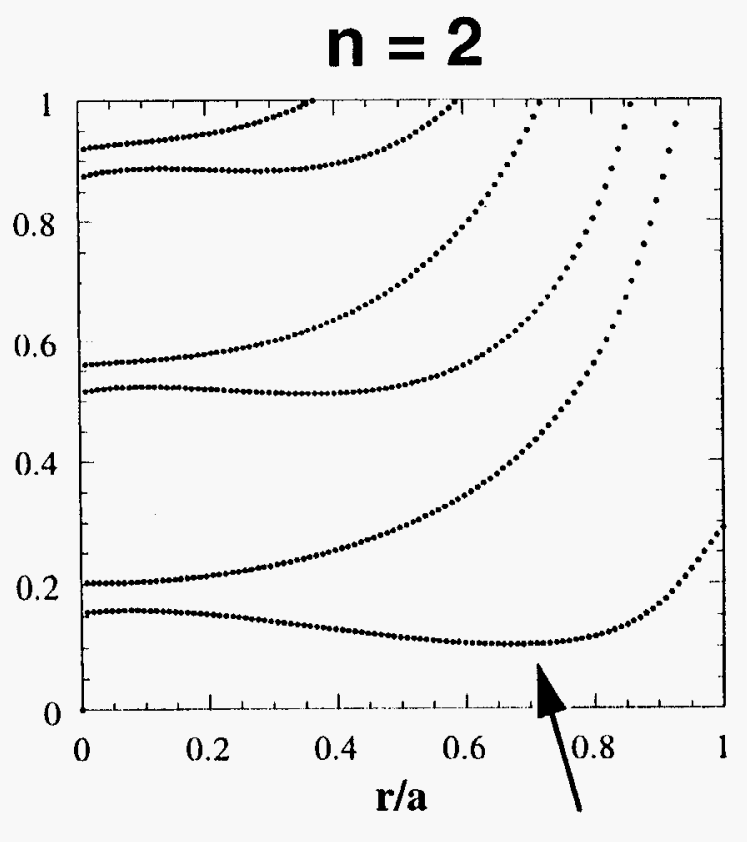

GAE

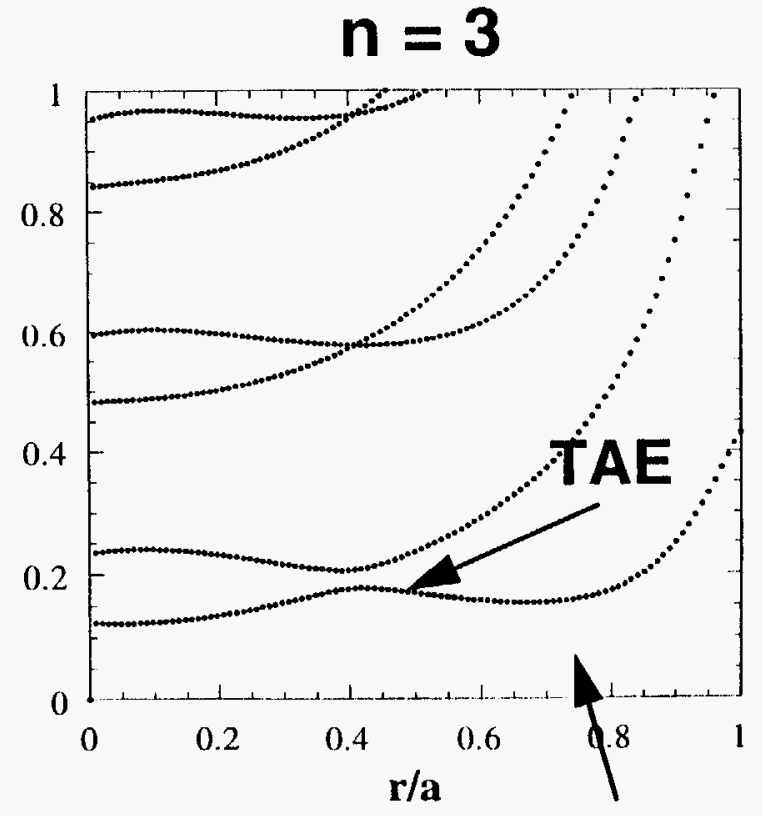

GAE 


\section{The GAE instability can be excited in low shear stellarators at relatively low values of $\mathbf{v}_{\text {hot }} / v_{\mathrm{A}}$.}

W7AS \#11474

(iota $>1 / 3$ )

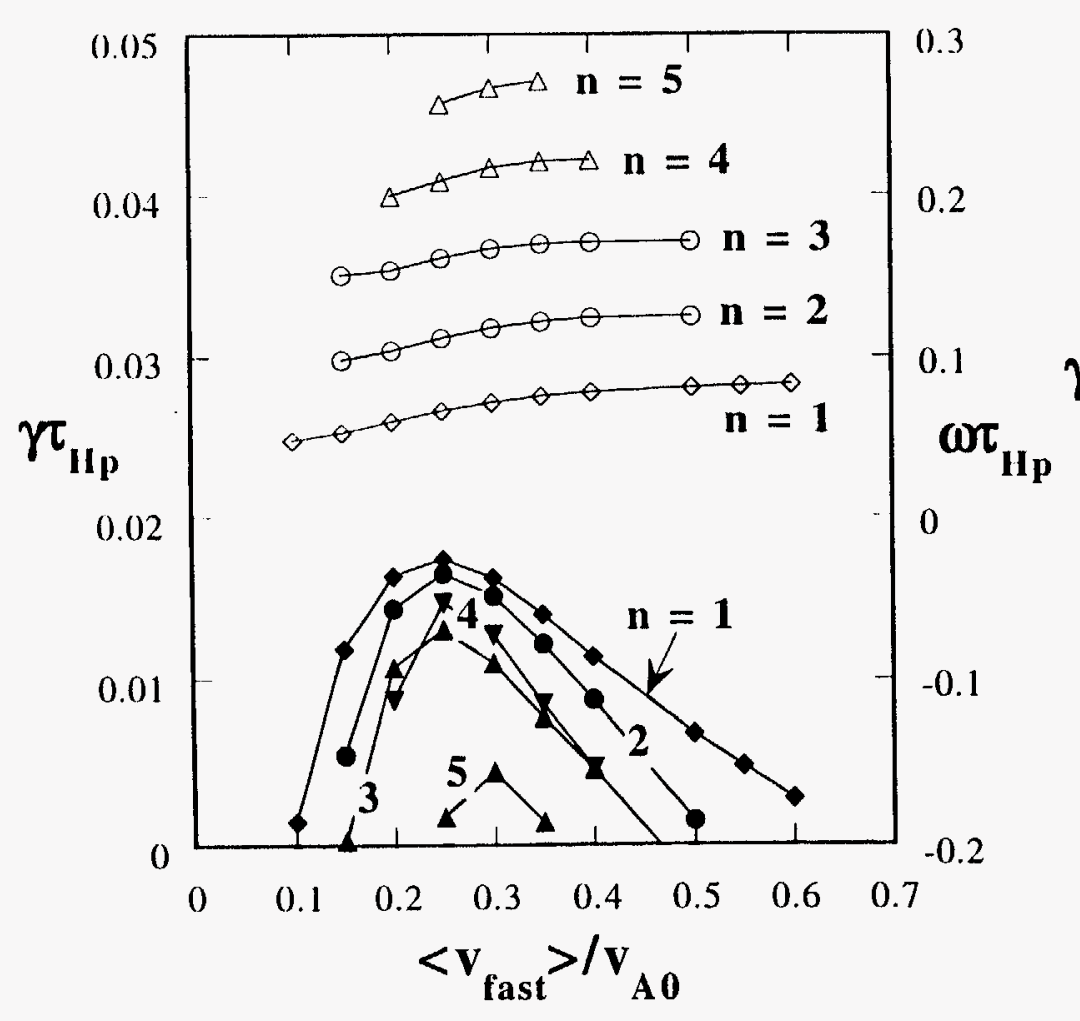

W7AS \# 19657

(iota $>1 / 2$ )

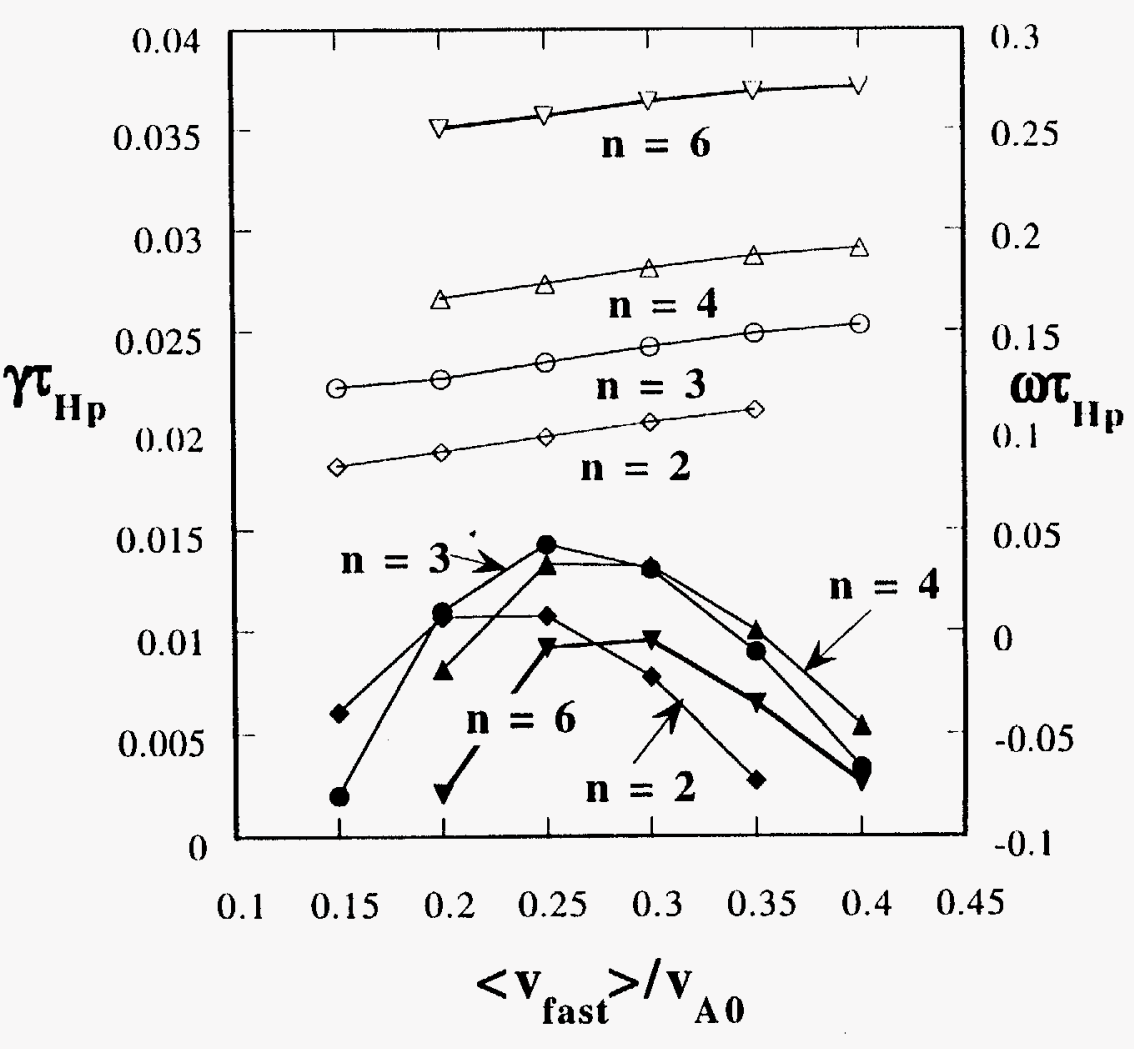


The following plots show the GAE 2-D mode structure for a W7-AS iota $>1 / 3$ case vs. toroidal mode number:
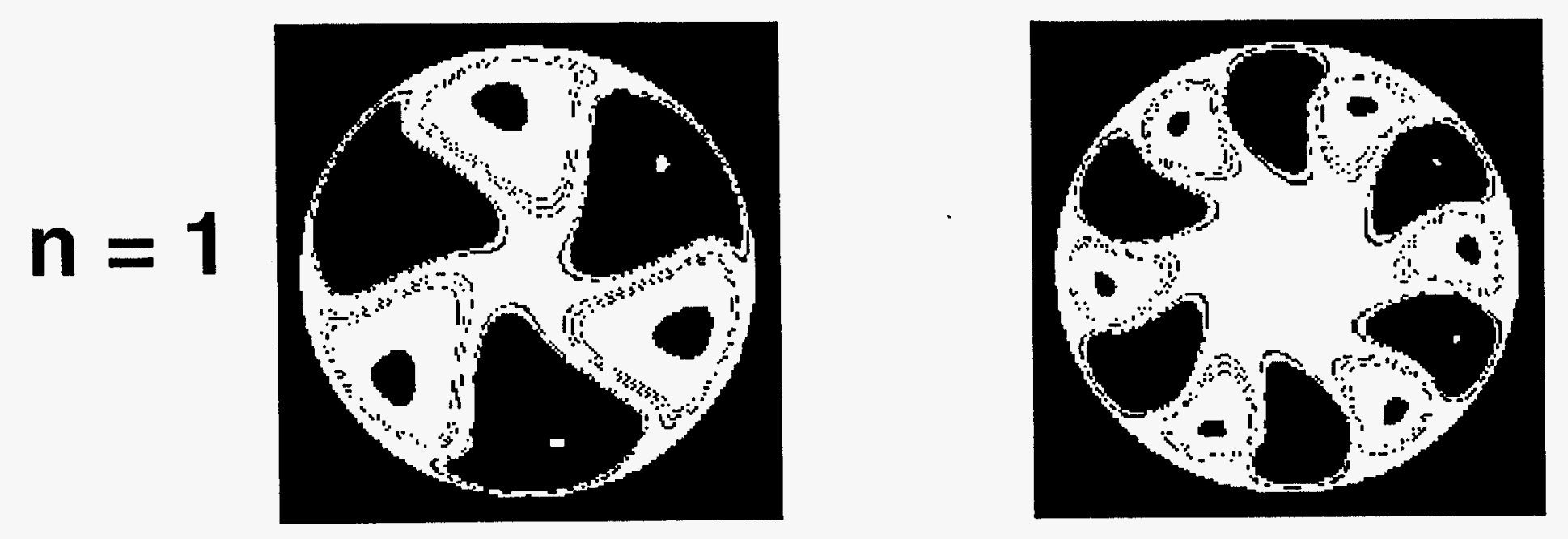

$n=2$
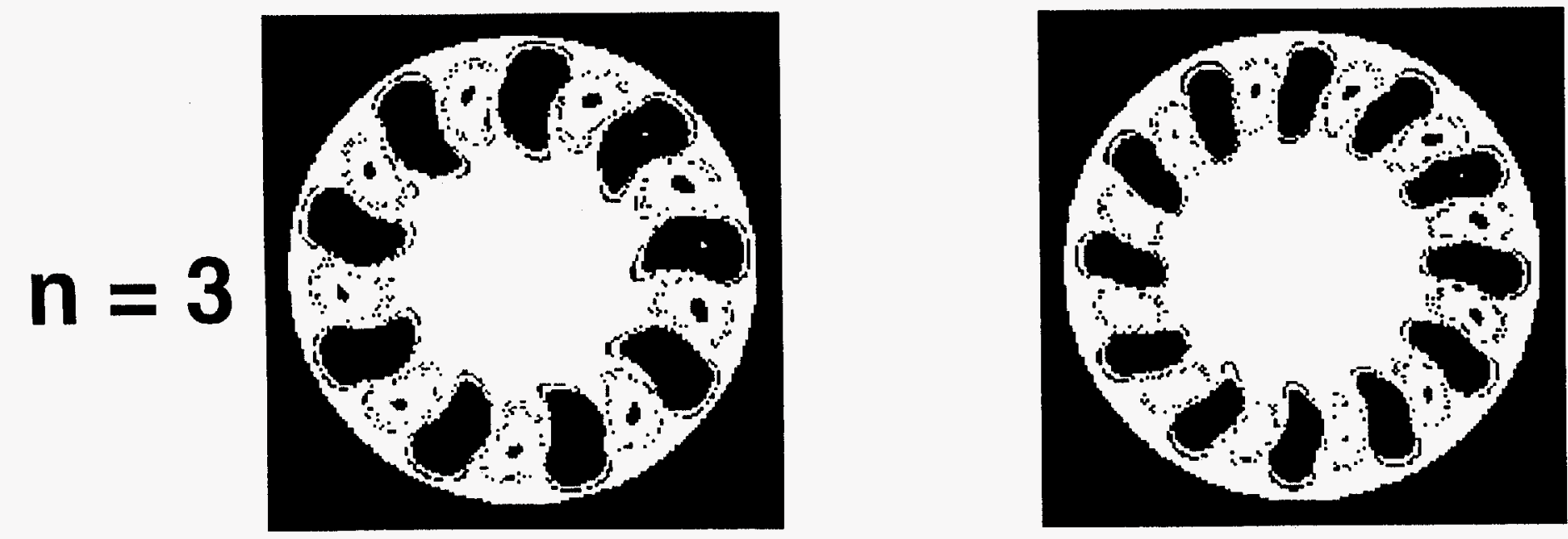

$n=4$ 

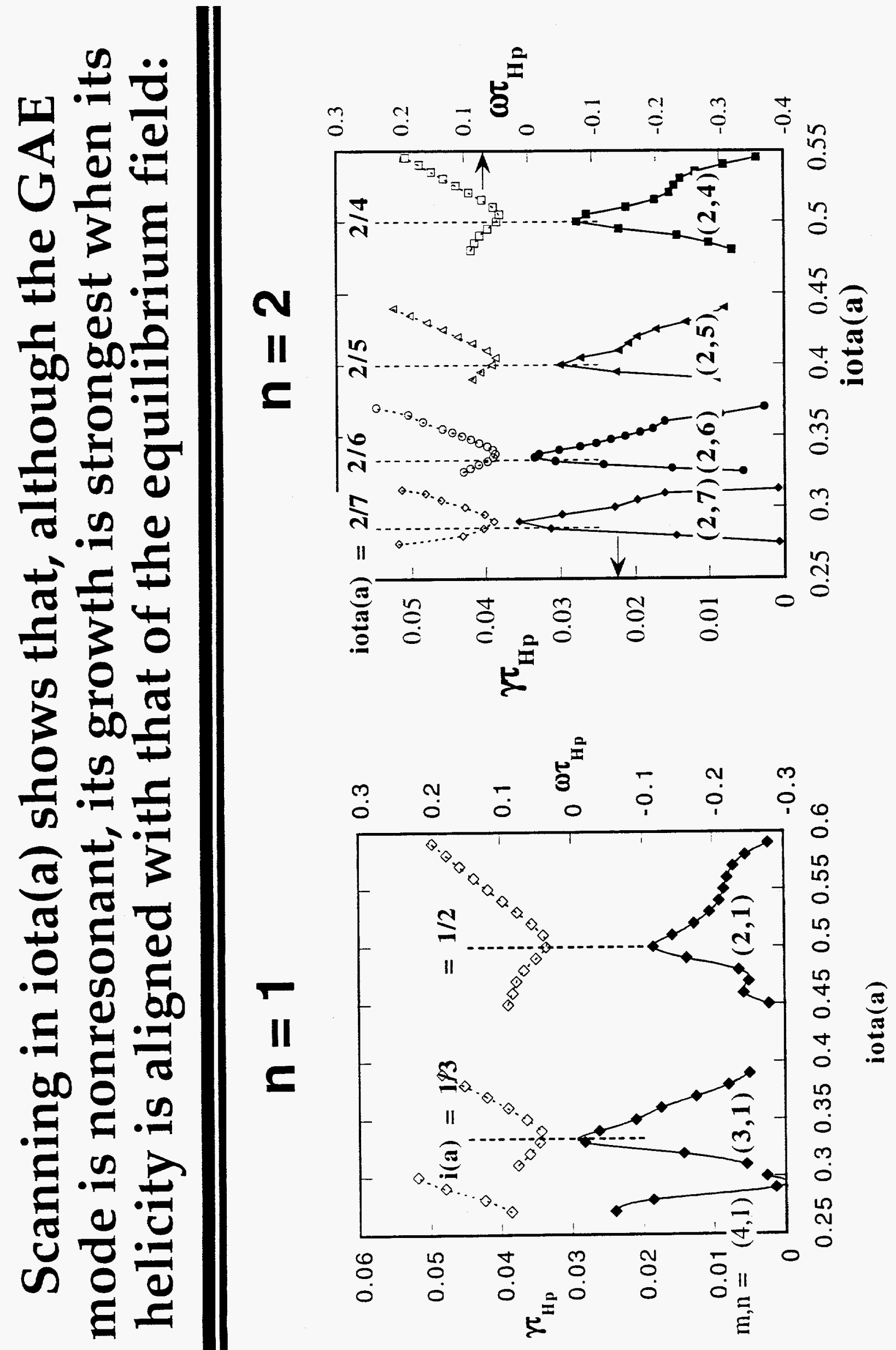


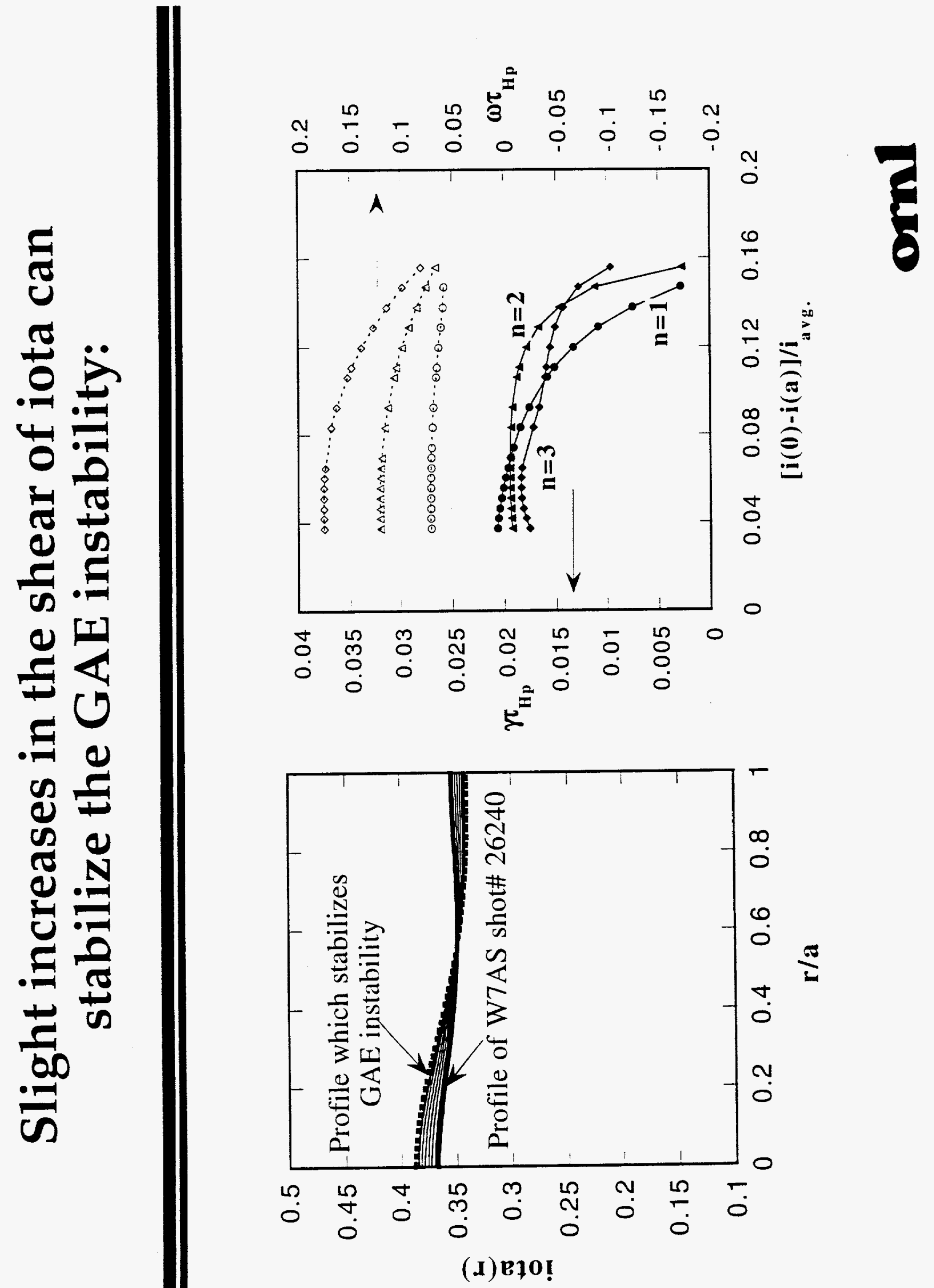




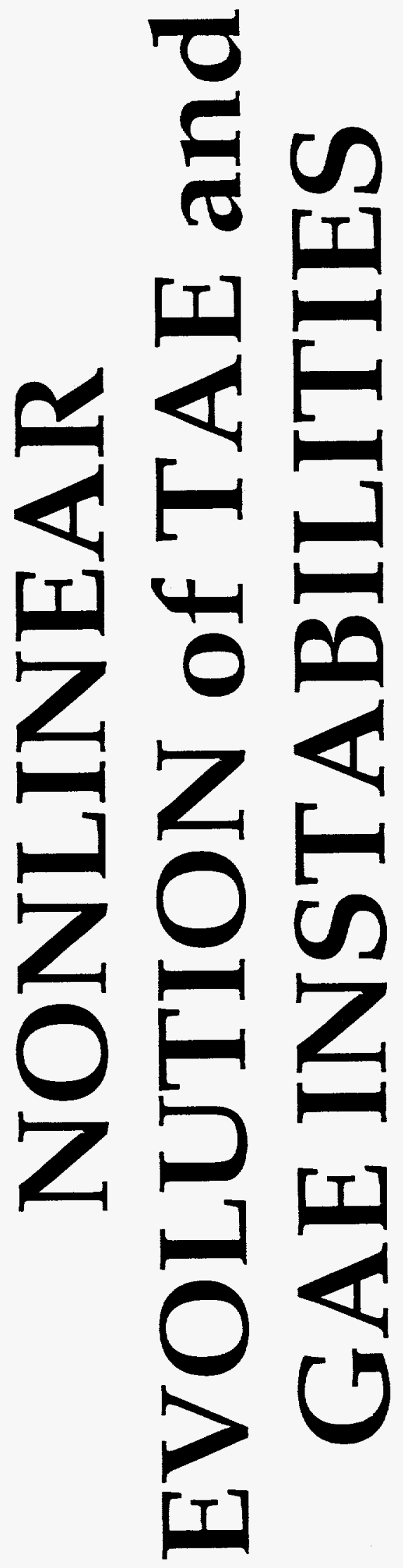




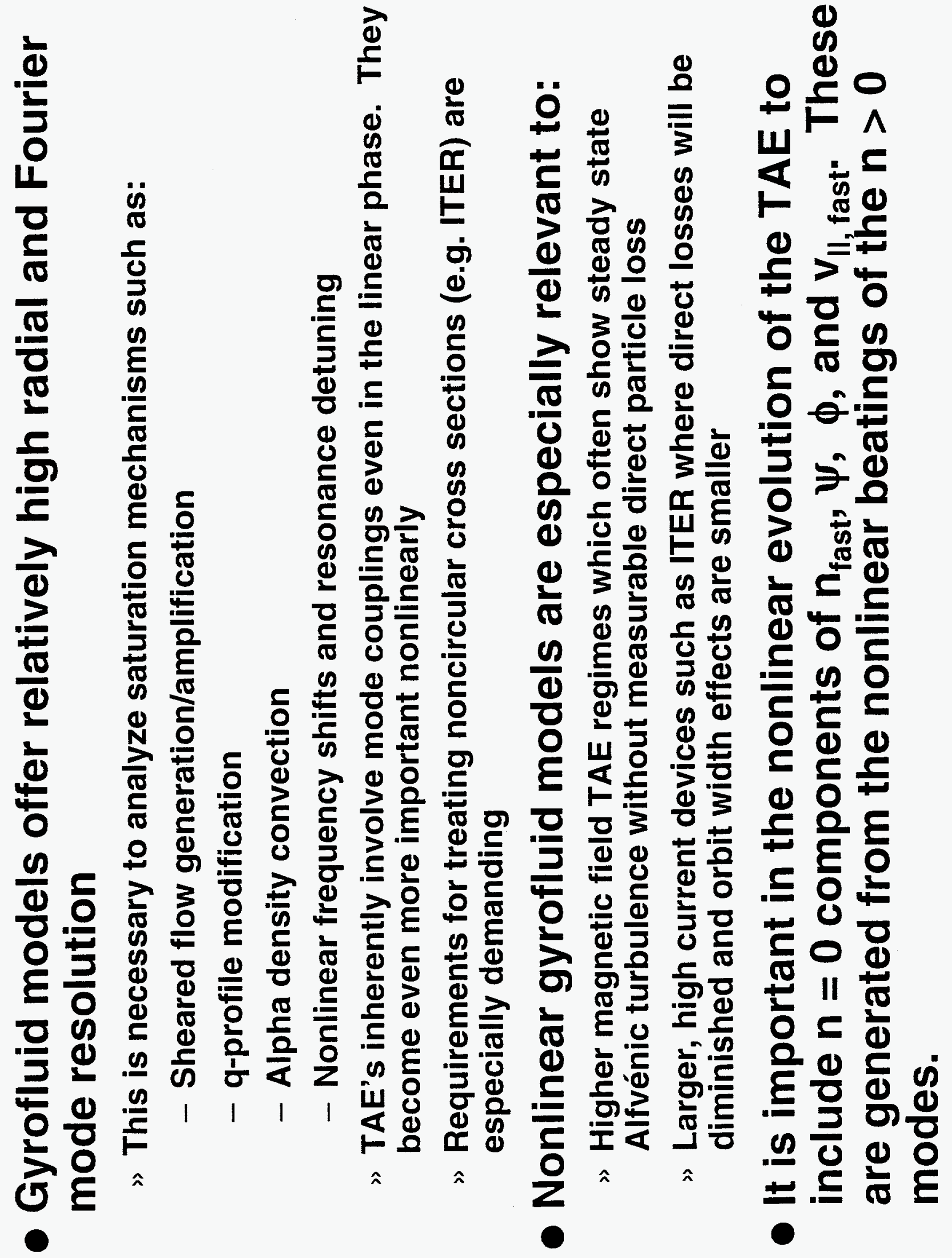




\section{The nonlinear saturated state of the TAE mode involves extensive coupling in both $\mathrm{m}$ and $\mathbf{n}$ (i.e., poloidal and toroidal mode numbers)}
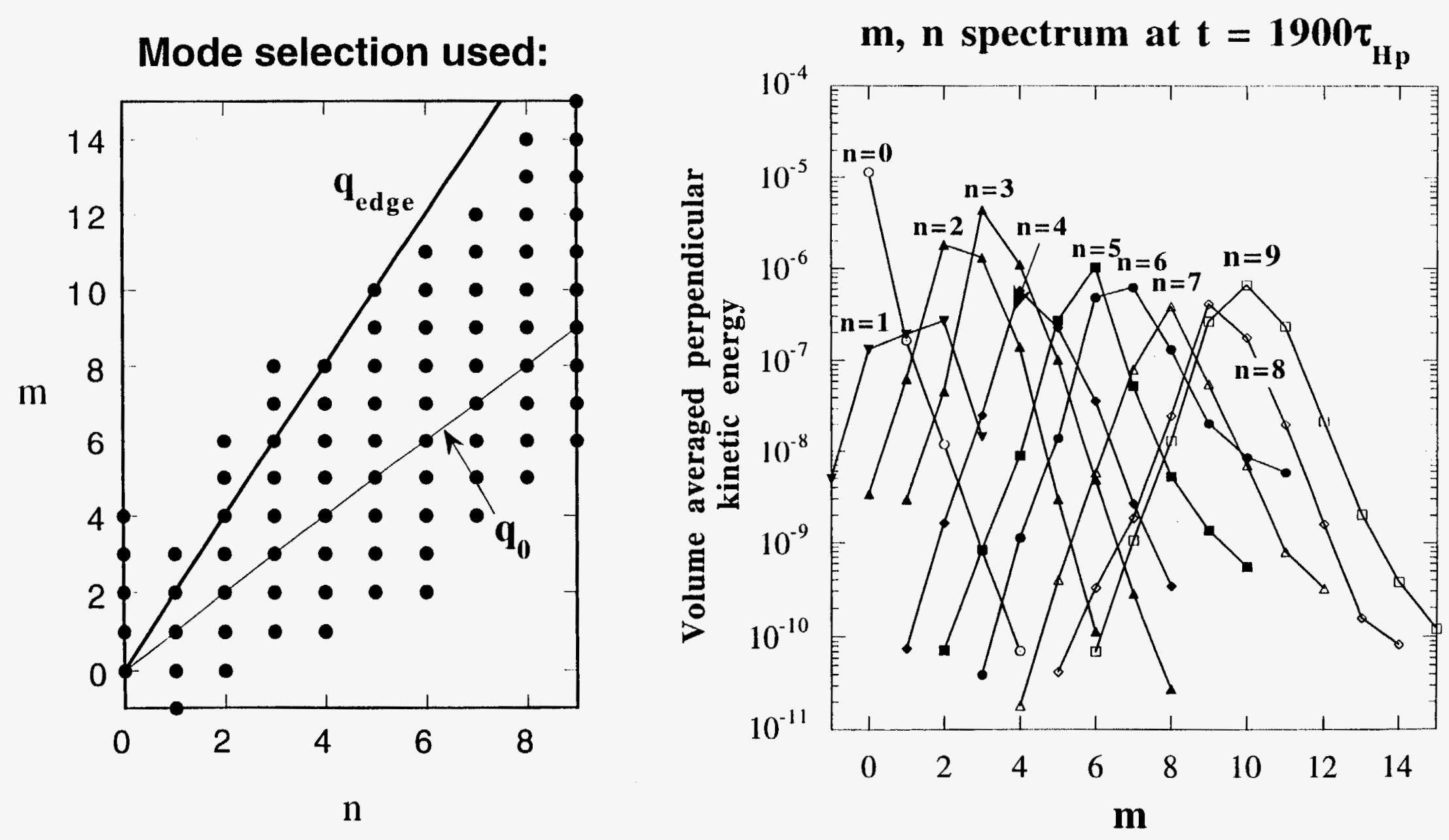


\section{Evolution of R.M.S. and volume averaged quantities shows dominance of the $n=0$ component in the nonlinear phase:}
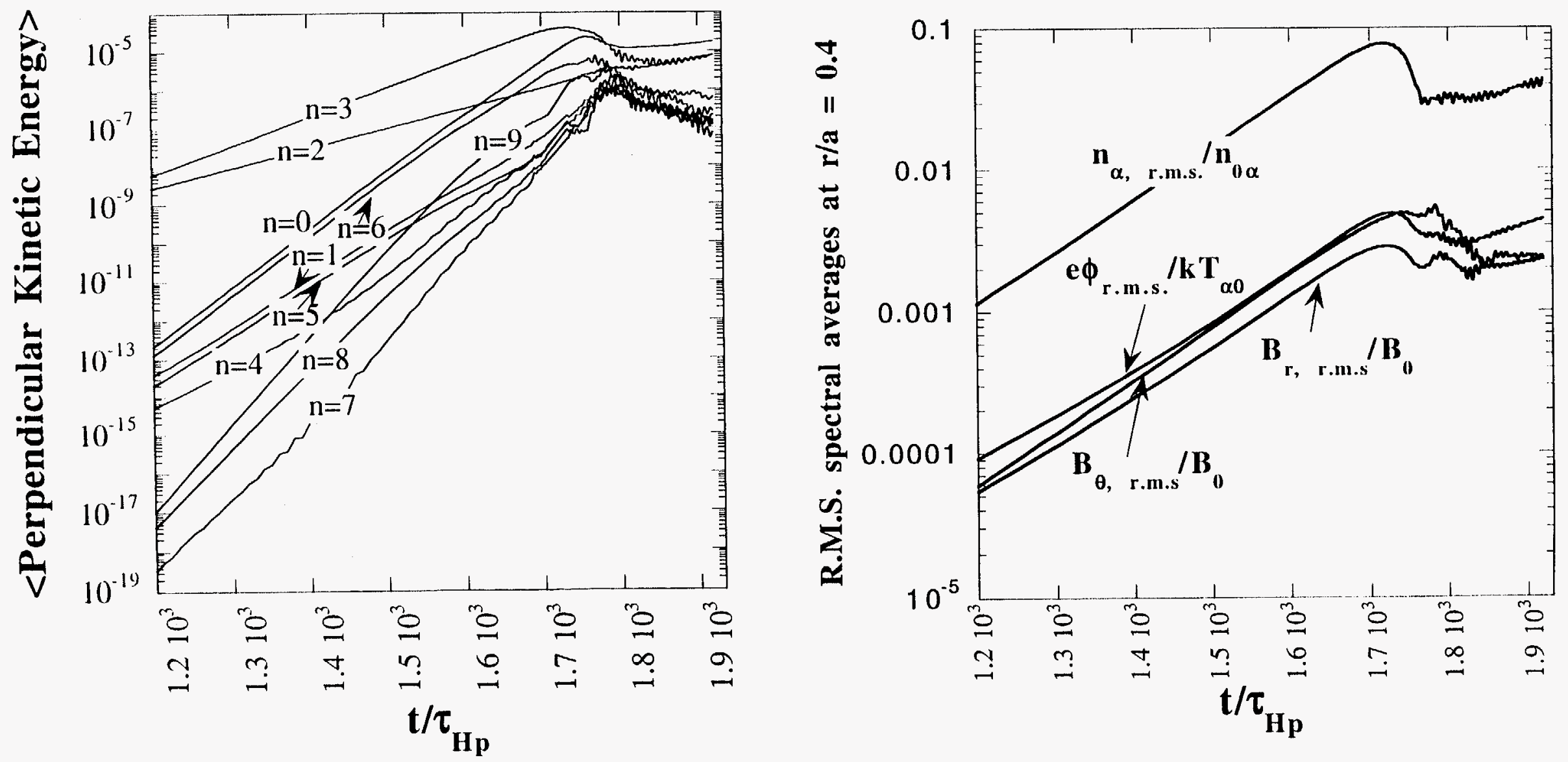


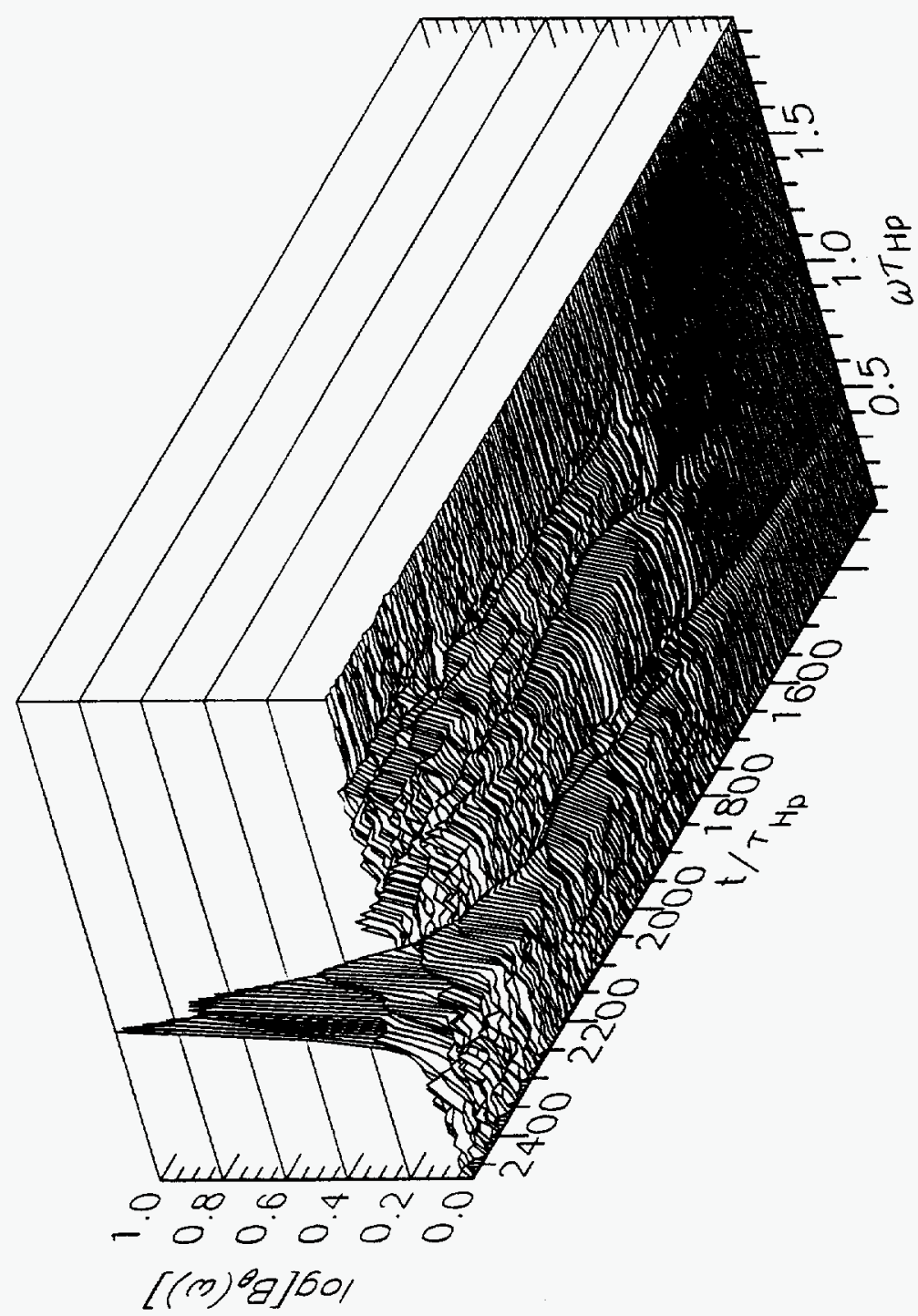




\section{The frequency peak for the GAE mode in the simulation is close to that observed in W7AS:}
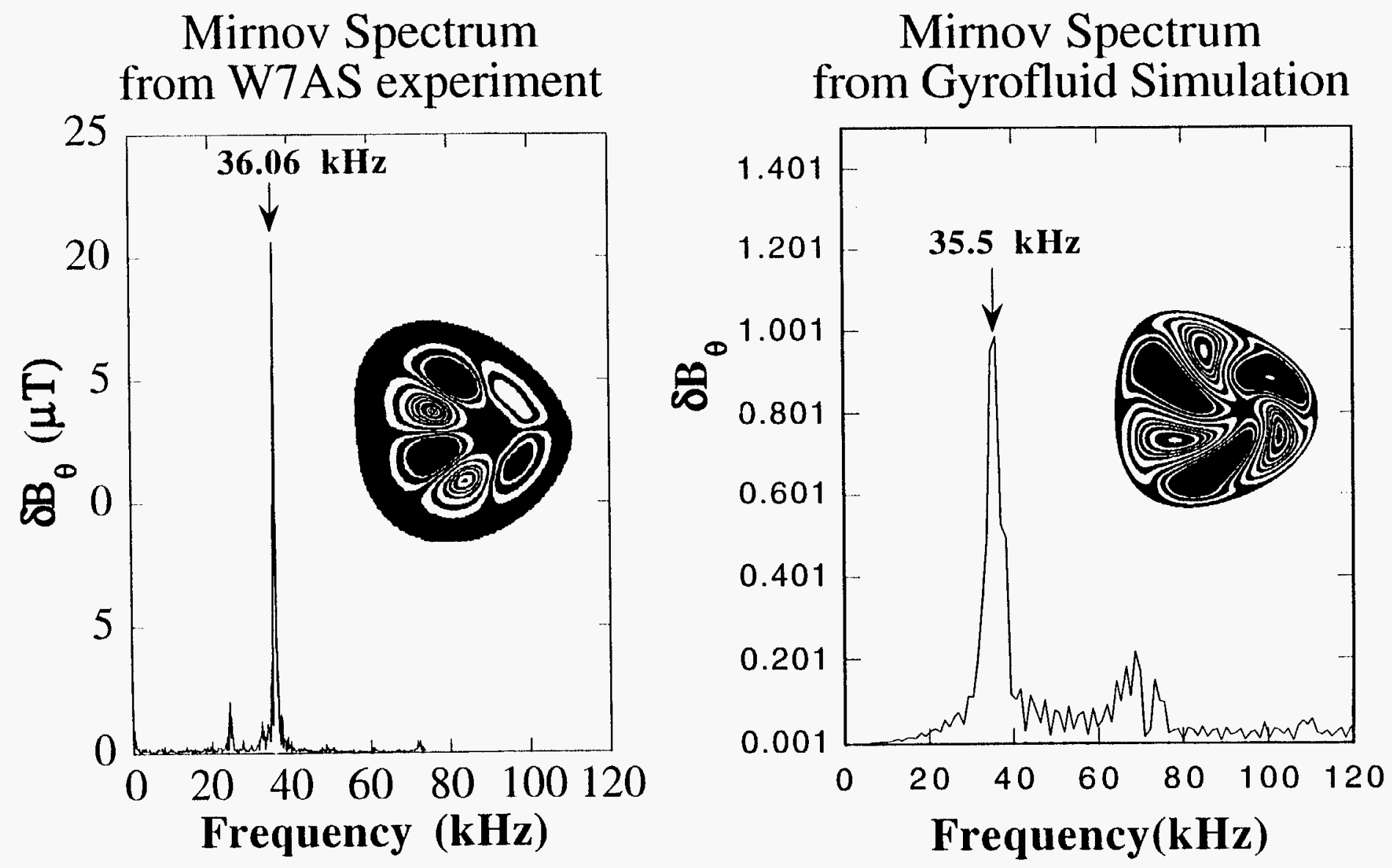


\section{The shear velocity flow effects are generated through the vorticity equation}

- Vorticity Equation: $\frac{\partial U}{\partial t}=-\frac{1}{c} R \vec{B} \bullet \vec{\nabla}\left(\frac{\tilde{J}_{\varphi}}{B_{\varphi}}\right)+\left[\hat{e}_{\varphi} \times \vec{\nabla}\left(\frac{R}{B_{\varphi}}\right)\right] \cdot \vec{\nabla} \tilde{p}_{\alpha}+\mu \nabla_{\perp}^{2} U$ where $\quad \mathrm{U}=\hat{\mathrm{e}}_{\varphi} \cdot\left[\vec{\nabla} \times\left(\frac{\rho_{\text {ion }} \mathrm{R}}{\mathrm{B}_{\varphi}^{2}} \vec{\nabla}_{\perp} \tilde{\phi} \times \hat{\mathrm{e}}_{\varphi}\right)\right]$

- Flow Evolution equation (flux surface average of vorticity equation):

$\frac{\partial}{\partial t}\left\langle\frac{\rho_{\mathrm{ion}} \mathrm{R}}{\mathrm{B}_{\varphi}} \mathrm{v}_{\theta}\right\rangle=\left\langle\frac{\mathrm{R}}{\mathrm{B}_{\varphi}} \frac{\partial \tilde{\mathrm{p}}_{\alpha}}{\partial \theta}\right\rangle-\left\langle\frac{1}{\mathrm{~B}_{\varphi}} \mathrm{J}_{\varphi, \mathrm{eq}} \frac{\partial \tilde{\psi}}{\partial \theta}\right\rangle+\left\langle\mathrm{U} \frac{\partial \phi}{\partial \theta}\right\rangle-\left\langle\frac{\tilde{\mathrm{J}}_{\varphi}}{\mathrm{B}_{\varphi}} \frac{\partial \tilde{\psi}}{\partial \theta}\right\rangle+\left\langle\mu \nabla_{\perp}^{2} \mathrm{U}\right\rangle$

\section{Linear terms} unique to toroidal geometry $\mathrm{m}>0$ equilibrium couples with $n=0, m>0$ fluctuations
Reynold's stresses (nonlinear) electrostatic and electromagnetic components
Viscous Damping 


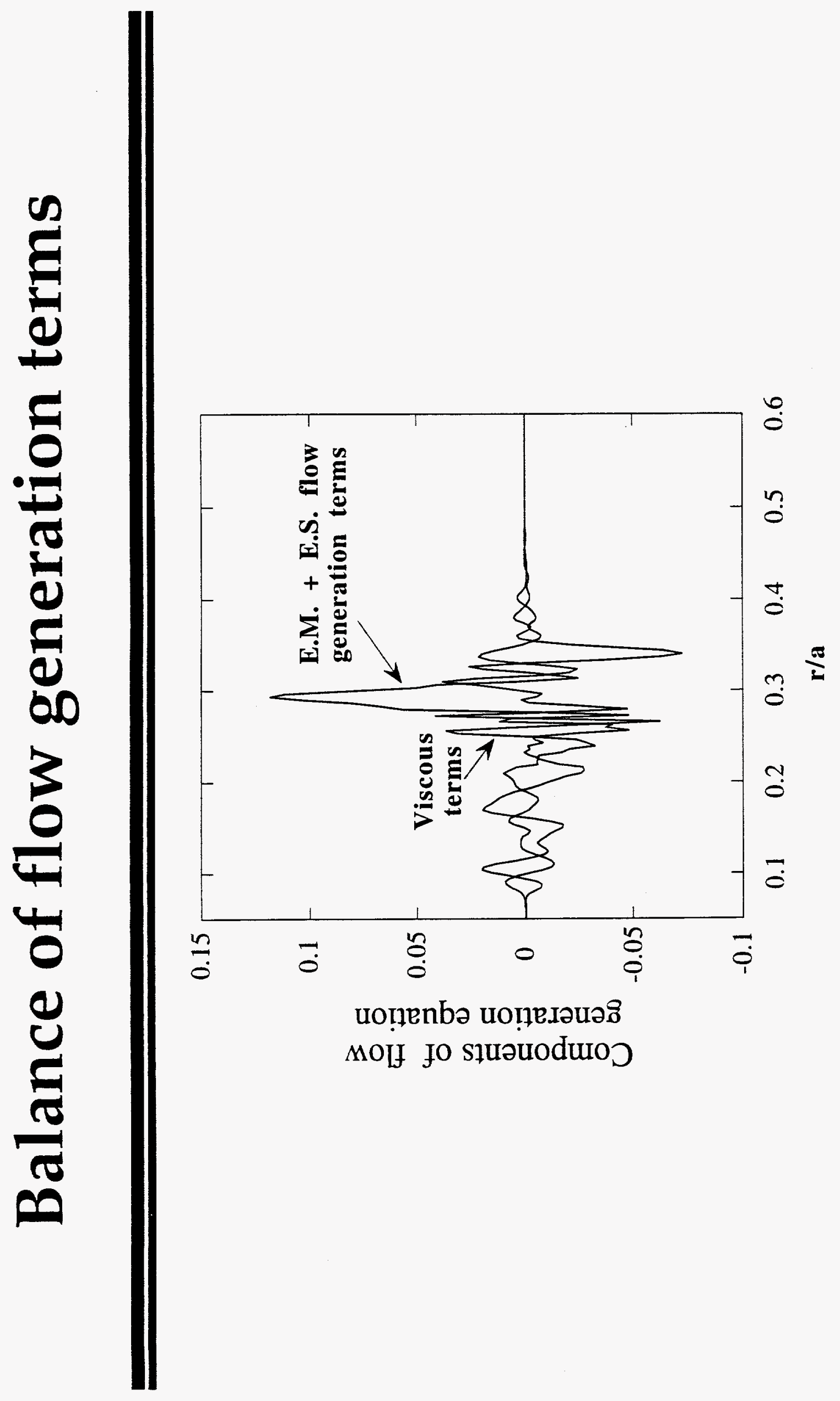




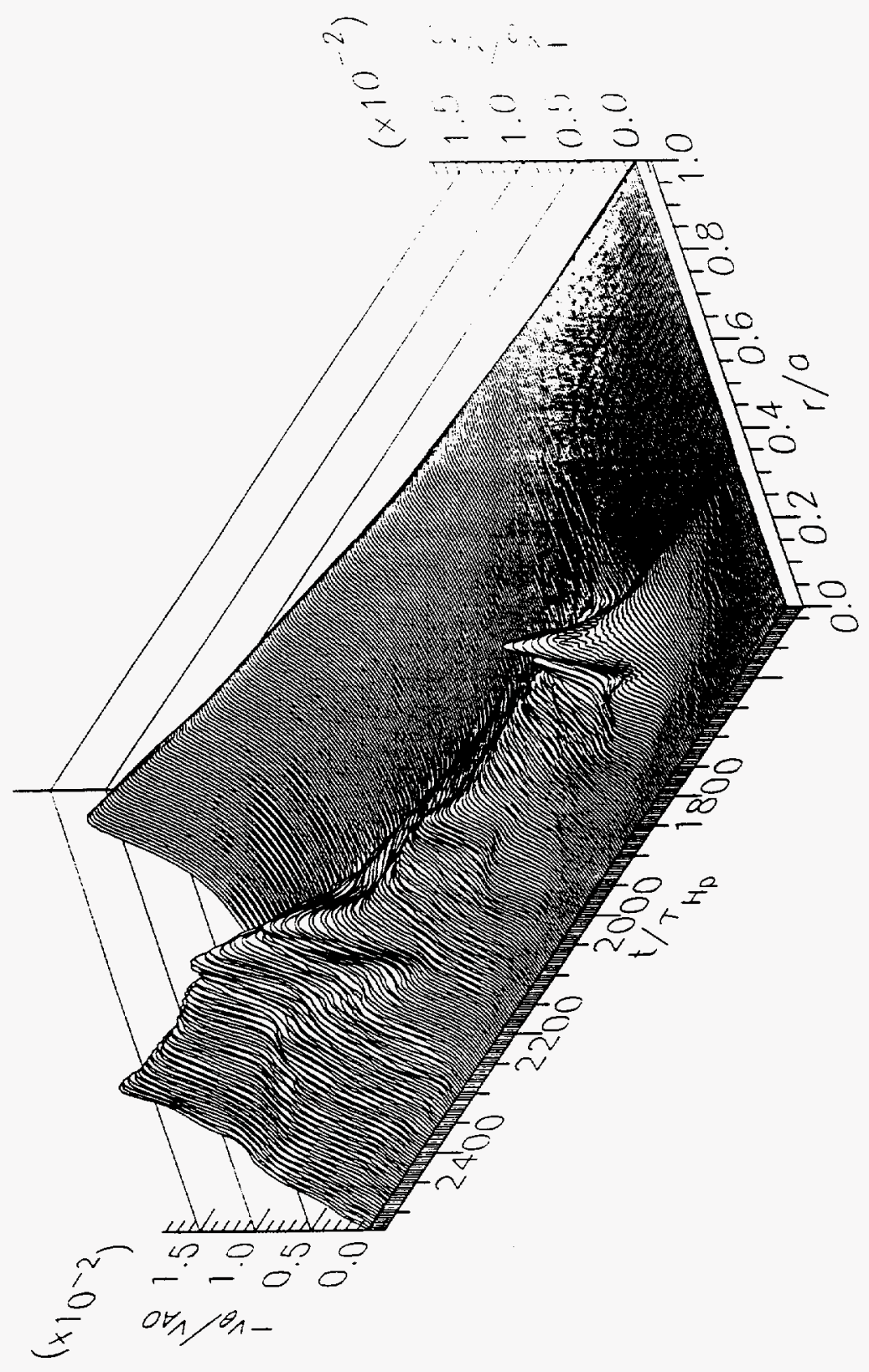




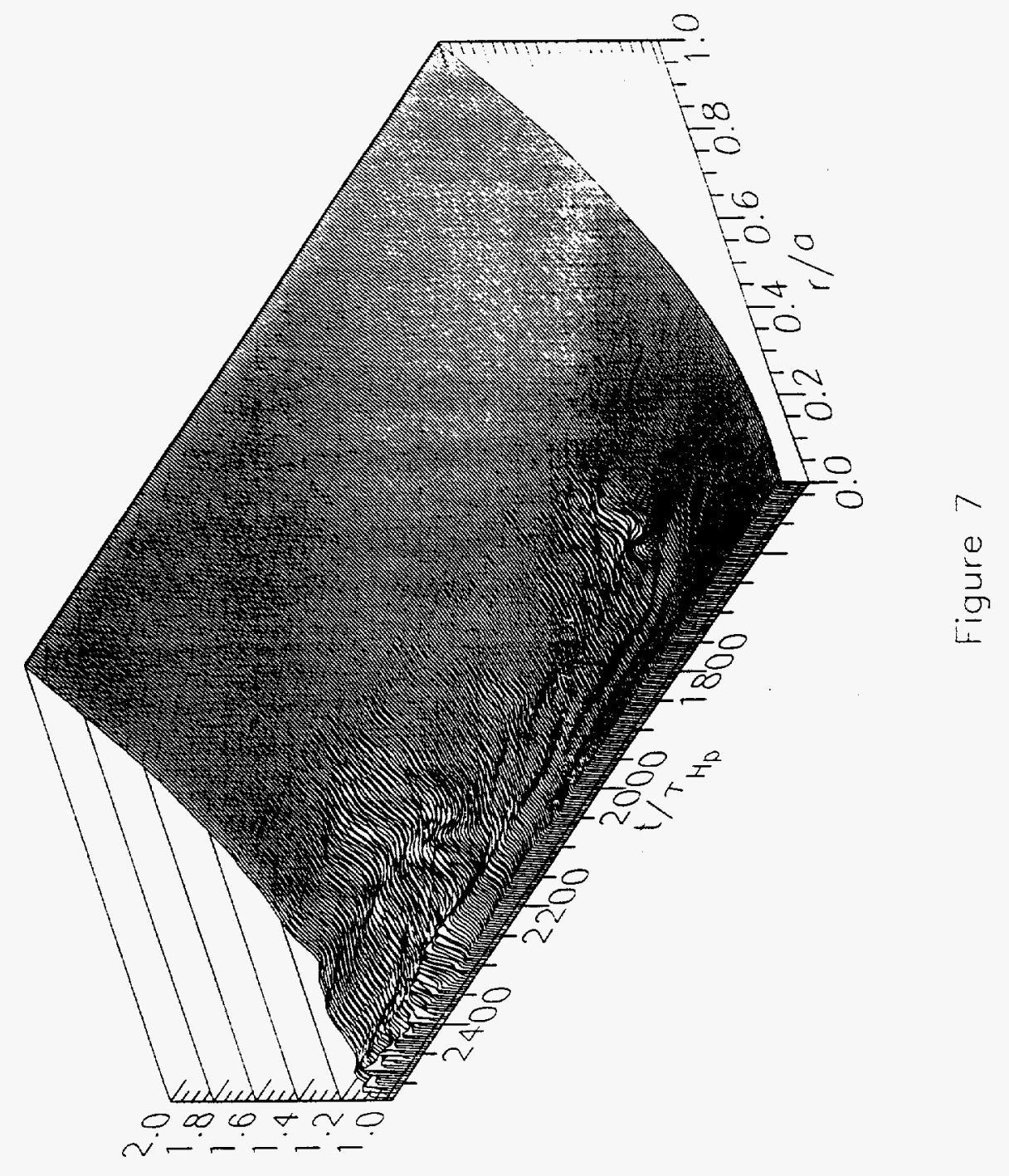




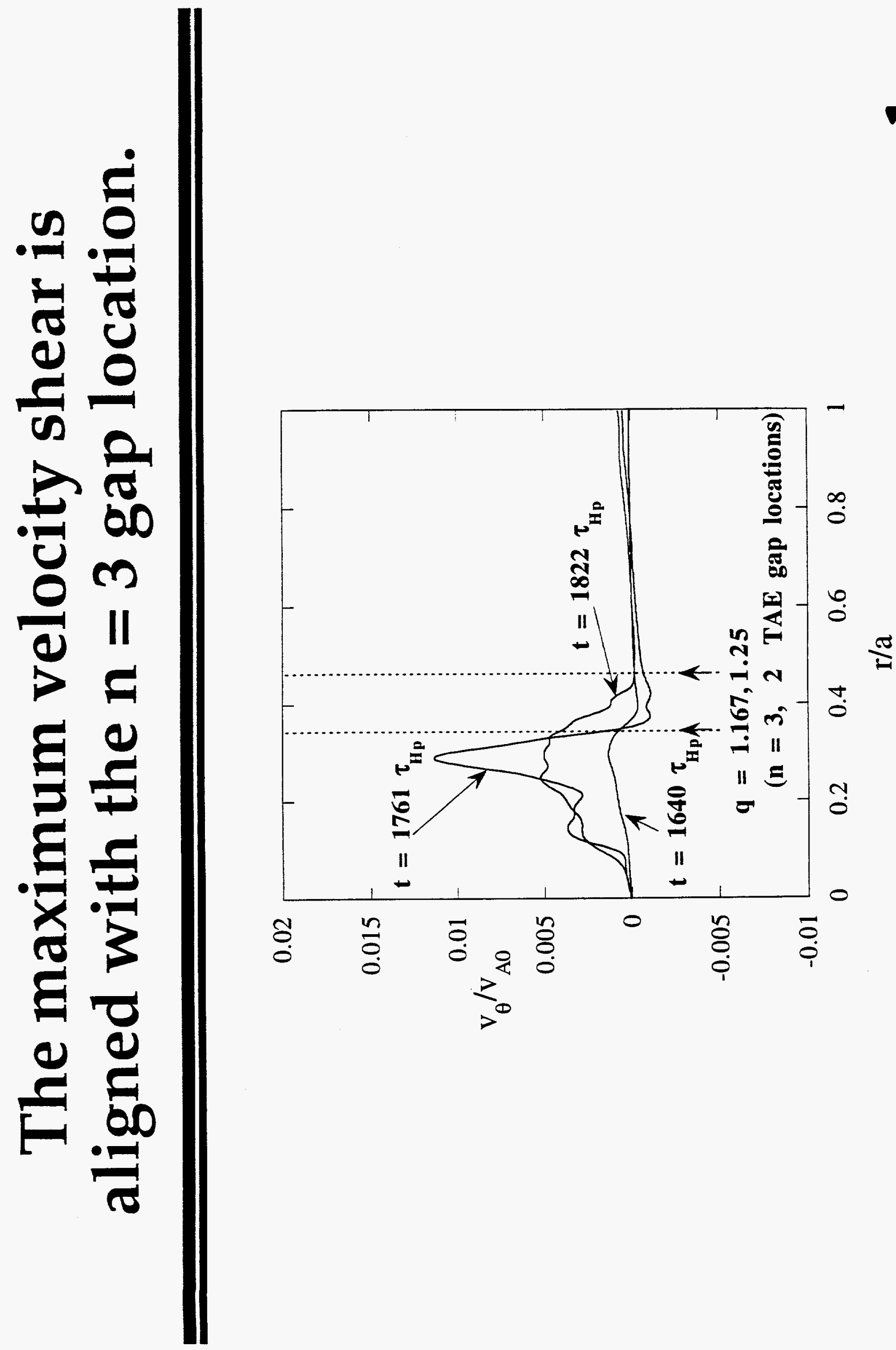




\section{The effect of the $n=0, m=0$ components can be diagnosed by examining their effect on linear growth rates}
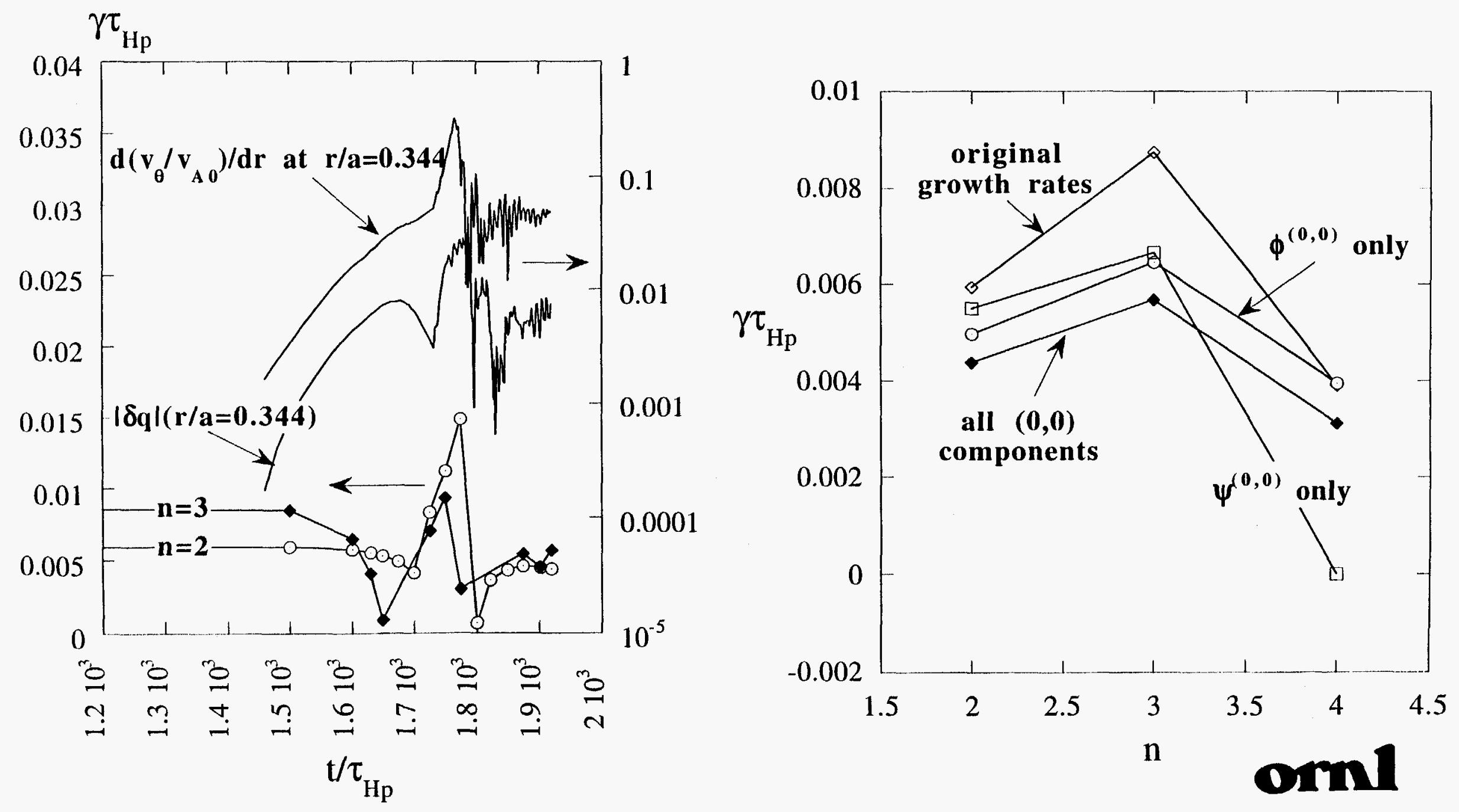


\section{CONCLUSIONS}

- Our model is consistent with beamdriven TAE thresholds on TFTR and DIII-D

- TFTR-DT supershots are predicted to be stable to $\alpha$-driven TAE's

- These thresholds can be lowered by:

" Raising $q(0)$ to around 1.5 (aligns gaps with max. $d p_{0} / d r$ ) (q-PROFILE CONTROL)

" Lowering $T_{\text {ion }}$, but need to maintain $\beta_{\alpha}$ (PELLETS, GAS PUFF)

"Vary $v_{\alpha} / v_{A}$ to enhance resonant coupling (DENSITY CONTROL)

"Above techniques can have future applications to He ash removal, burn control 


\section{CONCLUSIONS (Continued)}

- Our model indicates the GAE (Global Alfvén Mode) can be excited in low shear stellarators such as W7-AS

》 Excited for $\left\langle v_{\text {fast, ion }}>/ v_{A} \approx 0.15\right.$ to 0.4

" Growth rate shows broad, but resonant peaks with rational iotas

»Stabilized by shear in iota profile (e.g., from increasing $\beta$ )

"Issue for future devices: Will there be a stable window between GAE and TAE instabilities?

- The GAE (Global Alfvén Mode) can be induced in tokamaks if $q(r)$ is flat near the center

» Of concern for TPX, ITER where high bootstrap currents cause central weak negative shear regions 


\section{CONCLUSIONS (Continued)}

- Nonlinear TAE/GAE Behavior

"Simulations of edge magnetic fluctuation spectra with this model have shown similarities with experiments

» Nonlinear evolution is eventually dominated by the $\mathbf{n}=\mathbf{0}$ component

»Saturation mechanisms:

- sheared $\vec{E} \times \vec{B}$ flow generation/amplification

- q-profile modification

- $\overrightarrow{\mathrm{E}} \times \overrightarrow{\mathrm{B}}$ convection of $\alpha$ density

" Observed saturation suggests: TAE/GAE's can possibly be controlled by RF generated sheared flows. 